\title{
Developmental malformation of the corpus callosum: a review of typical callosal development and examples of developmental disorders with callosal involvement
}

\author{
Lynn K. Paul
}

Received: 1 June 2010 / Accepted: 13 August 2010 / Published online: 23 September 2010

(C) Springer Science+Business Media, LLC 2010

\begin{abstract}
This review provides an overview of the involvement of the corpus callosum (CC) in a variety of developmental disorders that are currently defined exclusively by genetics, developmental insult, and/or behavior. I begin with a general review of CC development, connectivity, and function, followed by discussion of the research methods typically utilized to study the callosum. The bulk of the review concentrates on specific developmental disorders, beginning with agenesis of the corpus callosum (AgCC) - the only condition diagnosed exclusively by callosal anatomy. This is followed by a review of several genetic disorders that commonly result in social impairments and/or psychopathology similar to $\mathrm{AgCC}$ (neurofibromatosis-1, Turner syndrome, 22q11.2 deletion syndrome, Williams yndrome, and fragile X) and two forms of prenatal injury (premature birth, fetal alcohol syndrome) known to impact callosal development. Finally, I examine callosal involvement in several common developmental disorders defined exclusively by behavioral patterns (developmental language delay, dyslexia, attention-deficit hyperactive disorder, autism spectrum disorders, and Tourette syndrome).
\end{abstract}

Keywords Corpus callosum $\cdot$ White matter $\cdot$ Brain connectivity $\cdot$ Neuroanatomy $\cdot$ Interhemispheric

\footnotetext{
L. K. Paul $(\bowtie)$

Division of Humanities and Social Sciences,

California Institute of Technology,

HSS 228-77, Caltech,

Pasadena, CA 91125, USA

e-mail: 1kpaul@hss.caltech.edu
}

\section{Why study the CC?}

The corpus callosum (CC) is unique to placental mammals and comprised of approximately $\sim 190$ million axons that connect the left and right hemispheres. The most parsimonious explanation for callosal evolution is that it arose to facilitate long-distance integration within large brains (Mihrshahi 2006). Across species, increases in cortical volume are positively correlated with increases in CC area and number of callosal fibers (Olivares et al. 2000, 2001; Killing and Insel 1999). However, the correlation is nonlinear and as a result, species with larger brains actually have proportionately reduced interhemispheric connectivity (Killing and Insel 1999; Witelson 1985, 1989; Aboitiz 1992; Aboitiz et al. 1992a, b, 1995; Dorion et al. 2000) and depend more heavily on intrahemispheric processing (Ringo 1994).

In the late 1960s, callosal transection was introduced as treatment for intractible epilepsy (Bogen 1985; Gordon and Sperry 1969; Milner et al. 1968; Sperry et al. 1974) and provided a radical foundation for exploring callosal functions in humans. Following surgery, these patients manifest a "disconnection syndrome" including absent callosal transfer of sensory information and deficits in bimanually coordinated motor activity. Additional symptoms, for example, anomia for objects held in the left hand, provided crucial insights about hemispheric specialization for uniquely human higher cognitive skills such as language (Bogen 1985; Gordon and Sperry 1969; Milner et al. 1968; Sperry et al. 1974). Although the behavior of adult callosotomy patients appeared remarkably "normal" outside of specific research paradigms, closer observation revealed a pattern of subtle social and emotional processing deficits resulting from disruption of long-range callosal connectivity (Hoppe and Bogen 1977; Bogen and Bogen 
1988). However, understanding the contribution of the CC to developmental disorders requires considerations of its development, rather than consequences resulting from transection in adults.

\section{Corpus callosum development}

There have been two main theories regarding the progression of callosal development in utero. For many years, the prevalent theory maintained that callosal axons first cross the midline toward the anterior end and callosal development proceeds posteriorly, with the rostrum added last (Byrd et al. 1978; Barkovich and Norman 1988; Rao and Harwood-Nash 1983). However, evidence from both earlier neuroanatomic literature and recent neuroimaging studies of human embryology indicates that callosal connections begin more centrally in the hippocampal primordium and the subsequent growth progresses bidirectionally both anterior and posterior, with more prominent anterior growth (Kier and Truwit 1996; Huang et al. 2009; Huang et al. 2006; Patten 1968; Hamilton et al. 1962; Carpenter and Sutin 1983; Barkovich et al. 1992).

Current data indicates that callosal development involves exuberant axon growth followed by a period of axonal pruning that extends from late in gestation through the first 2 postnatal months (Innocenti and Price 2005). In a human fetus, rudimentary CC fibers cross the midline by the 12th post-conceptual week (PCW; (Rakic and Yakovlev 1968; Kier and Truwit 1996). Growth of anterior sections is evident in the 14th-15th PCW and development of posterior sections begins by the 18th-19th PCW (Kier and Truwit 1996; Ren et al. 2006; Rados et al. 2006). By birth, cross-sectional area of the splenium and genu are uniform (Barkovich and Kjos 1988) and the splenial fibers have developed greater directional organization than the genu (Hofer and Frahm 2006).

The anterior and posterior callosal sectors are among the most rapidly developing white matter structures in humans. Increases in callosal fiber direction and external axonal structures (for example myelin) are visible in neuroimaging by 4 months, with the most significant increase in external axonal structures appearing between 13 and 18 months of age (Morriss et al. 1999). Throughout postnatal development, white matter maturation of the splenium generally precedes genu maturation, with posterior $\mathrm{CC}$ fiber structure remaining more directionally organized than the anterior $\mathrm{CC}$ into adulthood (Hofer and Frahm 2006). By 11 years, both the anterior and posterior callosum have reached $90 \%$ of their maximum fiber directionality, and by 20 years they have $90 \%$ of their maximum external axonal structures (Lebel et al. 2008).
Corpus callosum structure and function

The corpus callosum is topographically organized, such that fibers connecting a given cortical area are adjacent (Moses et al. 2000; Pandya et al. 1971; Witelson 1989; Tovar-Moll et al. 2007). Regional organization of the CC is most commonly described using the geometric classification scheme delimited by Witelson's histological studies. However, diffusion-weighted magnetic resonance imaging (dMRI) analyzed in conjunction with histologic data has provided clarification of callosal microstructure and connectivity, resulting in an updated variation of Witelson's segmentation (Fig. 1) (Hofer and Frahm 2006). Although Witelson's descriptions of cortical-callosal connections were not entirely accurate, her classification terms remain broadly accepted and will be used herein, but will be used in reference to the cortical-callosal connections described below.

The anterior one sixth of the CC (genu) contains the greatest density of thin neural fibers and primarily connects prefrontal association areas (Hofer and Frahm 2006), as well as the anterior inferior parietal regions (de Lacoste et al. 1985). The anterior body of the CC contains

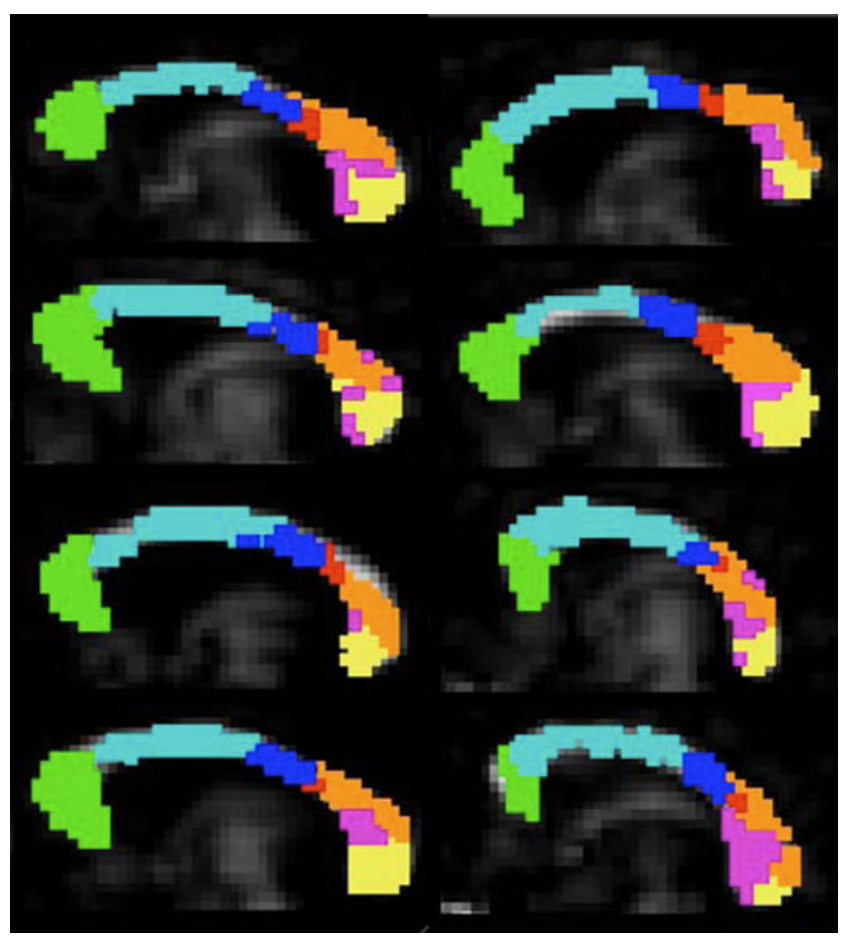

Fig. 1 Fractional anisotropy maps of mid-sagittal corpus callosum with overlay of all discernable fibers projecting out to specific cortical areas. Four female subjects on right and four male subjects on left. Color-scheme of projections is as follows: prefrontal lobe (green), premotor and supplementary motor areas (light blue), primary motor cortex (dark blue), primary sensory cortex (red), parietal lobe (orange), occipital lobe (yellow), and temporal lobe (violet). Extracted from Fig. 2 in (Hofer and Frahm 2006) 
Fig. 2 Examples of mid-sagittal MRI images and statistical outcomes from several of the conditions described in this review. All images are oriented with anterior to the left; a complete AgCC; b partial AgCC; c statistical significance of smaller CC area in 22qDS than controls (Fig. 4d in (Machado et al. 2007)); d CC hypoplasia in an individual born preterm (Fig. 2 in (Nosarti et al. 2004)); e significance of mean local CC area reveals significantly smaller anterior third of callosum in autistic subjects relative to control subjects (Fig. 2c in (Vidal et al. 2006))
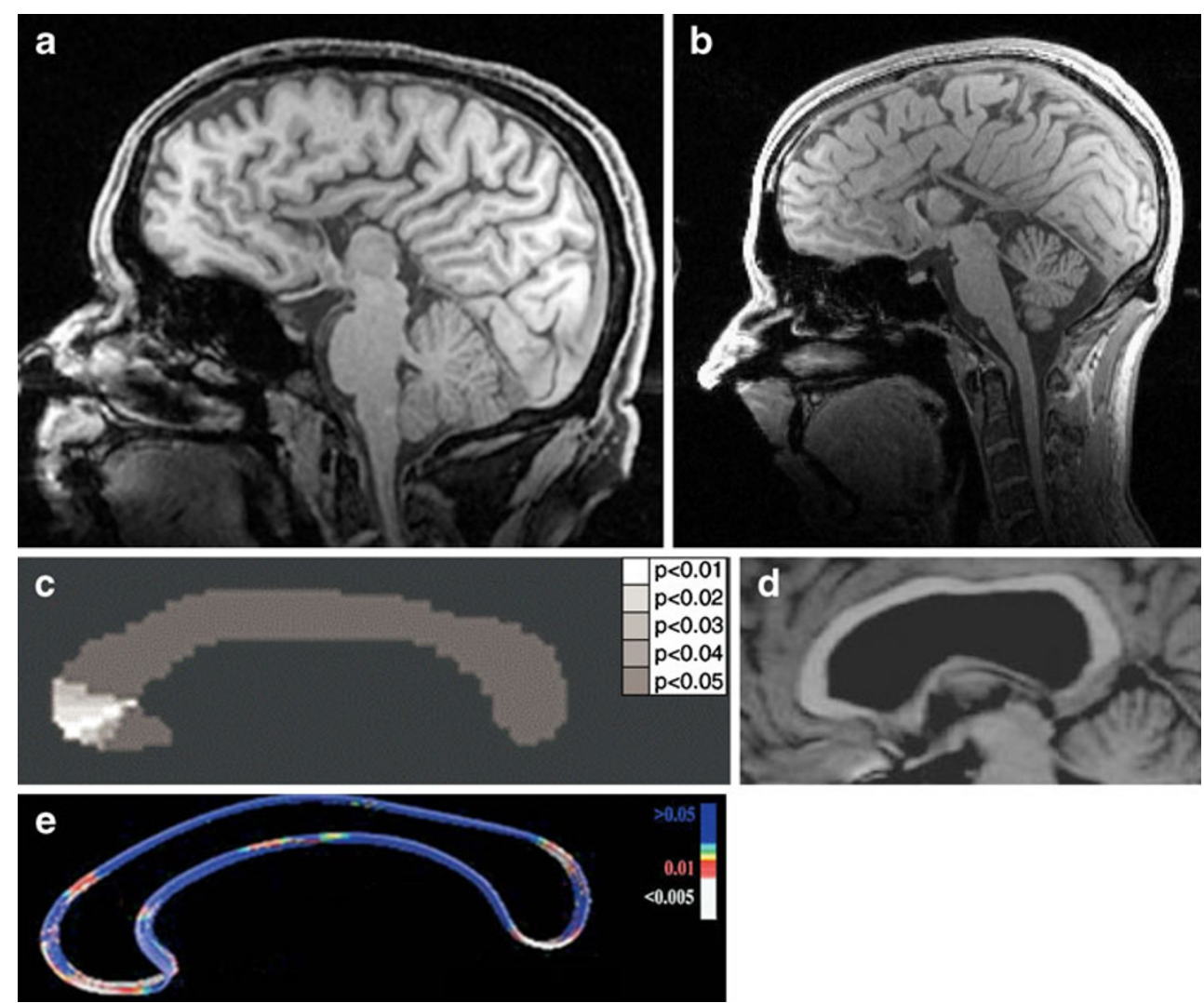

slightly larger and less densely packed fibers that connect premotor and supplementary motor areas and the posterior midbody connects primary motor areas via large highly myelinated and fast-conducting fibers (Hofer and Frahm 2006). Toward the posterior of the callosum, the isthmus is composed of midsized fibers that connect primary motor and primary sensory areas (Wahl et al. 2007). The anterior splenium contains thin fibers (similar to but less densely packed than those in the genu) connecting association areas of the parietal and temporal lobes (Hofer and Frahm 2006; Dougherty et al. 2005; Cascio et al. 2006; Huang et al. 2005). Finally, the posterior splenium is made up of large, highly myelinated and fast-conducting fibers from the occipital lobes (Huang et al. 2005; Hofer and Frahm 2006).

The high-density thin fibers of the genu and rostrum have low myelination and are slow-conducting, but their high density allows for refined topographic mapping (Aboitiz 1992). In contrast, rapid conduction via large highly myelinated fibers of the posterior midbody and posterior splenium aids in fusing lateralized sensory input. These large fibers make up a small percent of the CC fiber population $(<1 \%)$, with highest density in regions connecting auditory cortices, possibly facilitating interaural comparisons for auditory localization (Aboitiz 1992).

$\mathrm{CC}$ research typically involves one or more of the following: area measurements (commonly gathered from sagittal MRI or histological specimens), cellular and microstructural descriptions (based on histological staining or dMRI analysis), measures of functional connectivity (using behavioral paradigms, functional MRI, electroencephalography (EEG), magnetoencephalogram (MEG), and/or transcranial magnetic stimulation (TMS)), and histological studies. Of these methods, histological studies can provide the most detailed and concrete information about neural connections in an individual brain. However, complications due to cause of death, variations in brain fixation procedures and histological methodology, and small sample sizes can obfuscate the clinical relevance of these studies. As such, this review focuses on in vivo methods for callosal analysis. Here are a few comments about each of these in vivo measures, including methodological and interpretive considerations.

\section{Area measurements}

Callosal area is positively correlated with density of small fibers but is not correlated with density of large fibers (Aboitiz 1992; Aboitiz et al. 1992a). Thus measures of callosal area are likely to reflect axon density in the genu and anterior splenium, areas that connect association cortices. However, callosal area is not a meaningful indicator of axon density in the posterior midbody and posterior splenium, areas that connect primary motor cortices, and occipital lobes, respectively. 


\section{Microstructure}

Callosal microstructure is primarily studied via histology and dMRI. Studies integrating these methods may provide internal validation of their own findings (Jovanov-Milosevic et al. 2009; Huang et al. 2006; Ren et al. 2006). However, often dMRI results are used independently and may be overinterpreted. Thus, a critical reader should understand the meaning of dMRI measurements that are being reported, as well as the limitations of this methodology.

One particular model of dMRI data, the diffusion tensor, is now well established. It provides two main measures, anisotropy (often called fractional anisotropy (FA) or relative anisotropy (RA)) which indexes the degree of directionality or axon alignment in a tissue sample, and diffusivity (often called mean diffusivity (MD) or average estimated diffusivity (AED)) which indexes the degree to which cells restrict movement of water within a fiber sample. Higher anisotropy indicates greater alignment of fibers. Higher diffusivity indicates less developed cellular structure, such as reduced myelination or limited number of cells. FA values of CC regions correspond closely with fiber composition. Callosal areas with smaller densely packed fibers have high FA (genu and splenium) (Hofer and Frahm 2006), which suggests that FA in the $\mathrm{CC}$ is a closer indication of fiber density than of degree of myelination or axon diameter (Wahl et al. 2007).

The directional information from dMRI can also be integrated through space, in a process referred to as virtual fiber tractography. MRI fiber tractography is now widely used to map non-invasively the long-range structural connectivity of the human brain and it works very well for identifying larger fiber tracts that are highly organized in a single direction. However, current fiber tracking algorithms are inadequate for following multiple fiber paths when they pass through the same area. This so-called crossing fiber problem (Basser et al. 2000; Wiegell et al. 2000; Behrens et al. 2007) is the primary limitation for tracing the fibers of the $\mathrm{CC}$ out of the $\mathrm{CC}$ proper (Basser et al. 2000; Hofer and Frahm 2006; Johansen-Berg et al. 2007). Tractography identifies CC connections to the dorsal and medial cortical surface (for example, see Fig. 1) but does not reveal lateral callosal projections, presumably because lateral callosal projections cross through association fiber bundles with different orientations (for example, the longitudinal fasciculus and internal capsule). Despite this limitation, several recent studies have used dMRI and tract-tracing statistics to segment callosal regions according to the cortical areas they connect in an individual subject (Cascio et al. 2006; Huang et al. 2005; Dougherty et al. 2007). This approach has great promise when used wisely, remembering that lateral callosal projections are likely to be under-represented.
There is evidence that callosal microstructure correlates with cognitive test performance in adolescents (ages 1618 years). Specifically, FA in the body of the callosum ( middle third) correlated positively with copy accuracy of a complex figure. FA in the splenium was positively correlated with processing speed, expressive vocabulary and single-word reading. Regression analyses confirmed that visuospatial performance was associated with FA in the body of the $\mathrm{CC}$, whereas language performance (expressive vocabulary and single-word reading) was associated with FA in the splenium (Fryer et al. 2008).

\section{Functional connectivity}

The corpus callosum contains both homotopic and heterotopic interhemispheric connections, with a preponderance of the former. Although some callosal connections are inhibitory (allowing the hemispheres to inhibit each other to maximize independent function), the majority are excitatory (integrating information across hemispheres) (Bloom and Hynd 2005) and thus most research on functional callosal connectivity examines excitatory interhemispheric transfer (IHT). Efficiency of callosal transfer and of callosal inhibition are inferred from various behavioral paradigms, as well as from neural activation studies using functional MRI, MEG, EEG, and/or transcranial magnetic stimulation. By correlating functional connectivity and callosal structure measures such as FA or developmental stage, we gain insight about how callosal structure impacts behavior.

In healthy individuals, all callosal fibers are present at birth and functional connectivity via the $\mathrm{CC}$ increases as these fibers myelinate from about 4 postnatal months into young adulthood (Giedd et al. 1999). Cross-sectional data from children indicates that callosally mediated interhemispheric transfer of motor information increases from ages 4 to 11 years, with evidence of bimanual interference (typical in adults) emerging around age 6 (Franz and Fahey 2007). Developmental studies in children over age 6.5 years suggest that callosal maturation results in faster interhemispheric conduction of early visual evoked potential components that index sensory activity in the extrastriate visual cortex, resulting in improved ability to integrate bilaterally presented visual information (Hagelthorn et al. 2000) and greater recruitment of callosal connectivity to aid in processing computationally complex information (Banich and Brown 2000). These examples offer evidence that callosal functioning develops in parallel with its microstructure in early childhood (Lebel et al. 2008).

The crossed-uncrossed difference (CUD) is a very simple behavioral measure that indexes callosal facilitation as the additional time needed for crossed (left visual hemifield / right hand, right hemifield/left hand) compared with uncrossed (left hemifield/left hand, right hemifield/right 
hand) responses (Clarke and Zaidel 1989). Larger CUD indicates reduced callosal facilitation. In typical adults CUD correlated positively with diffusivity and negatively with FA of the total CC, genu and splenium, and was best predicted by diffusivity in the genu (Schulte et al. 2005). This suggests that the CUD may be used as an index of interhemispheric functional connectivity primarily in premotor and supplementary motor areas (genu) and visualprocessing areas (splenium).

Interhemispheric inhibition (IHI) has been measured using paired pulse TMS of M1 hand areas. The effectiveness of IHI between the M1 hand areas correlated positively with FA values of the hand-related callosal motor fibers. This finding supports the expectation that greater CC fiber density (indexed by FA) results in stronger IHI and lower IHI threshold (Wahl et al. 2007).

\section{Agenesis of the corpus callosum}

The most extreme form of developmental malformation of the corpus callosum is agenesis (for a detailed review see Paul et al. 2007). Agenesis of the corpus callosum (AgCC), including both complete and partial callosal absence, is an anatomically defined condition that result from disruption of the early stages of fetal callosal development. The diagnosis is based on a finding of absent callosal fibers as visualized through neuroimaging (ultrasound, CT, or MRI). $\mathrm{AgCC}$ is typically accompanied by a characteristic dilatation of posterior lateral ventricles (colpocephaly; (Baker and Barkovich 1992; Mori 1992) and often the presence of atypical fiber bundles (Probst Bundles) that run anterior to posterior just lateral to the interhemispheric fissure (TovarMoll et al. 2007). Recent neonatal and prenatal imaging studies suggest that AgCC occurs in at least 1:4,000 live births (Glass et al. 2008; Wang et al. 2004), and other imaging studies (Bodensteiner et al. 1994; Jeret et al. 1985) have demonstrated that $3-5 \%$ of individuals assessed for neurodevelopmental disorders have AgCC.

Complete and partial $\mathrm{AgCC}$ can result from genetic, infectious, vascular, or toxic causes (see (Paul et al. 2007) for review). Current evidence suggests that a combination of genetic mechanisms, including single-gene Mendelian, single-gene sporadic mutations and complex genetics (which may have a mixture of inherited and sporadic mutations) may be involved in the etiology of $\mathrm{AgCC}$. For approximately $30-45 \%$ of individuals with $\mathrm{AgCC}$, the cause is identifiable $(\sim 10 \%$ have chromosomal anomalies and the remaining $20-35 \%$ have recognizable genetic syndromes; (Bedeschi et al. 2006). However, if we only consider individuals with complete $\mathrm{AgCC}$, then the percentage of patients with identifiable syndromes drops to $10-15 \%$. Research on the cognitive and behavioral consequences of $\mathrm{AgCC}$ typically excludes patients with concomitant structural abnormalities such as polymicrogyria, pachygyria (abnormally broad gyri), heterotopia, and variability of anterior commissure structure (Shevell 2002; Goodyear et al. 2001; Hetts et al. 2006), so as to better isolate the impact of callosal absence.

The importance of developmental neural plasticity is clearly evident in comparison of individuals with $\mathrm{AgCC}$ and callosotomy patients. Surgical severing of callosal and other commissures in adolescents and adults results in a "disconnection syndrome" that includes absent callosal transfer of sensory information (Bogen 1979; Bogen 1985; Lassonde et al. 1991) and deficits in bimanual motor coordination (Zaidel and Sperry 1977). In contrast, patients with callosotomy in childhood and individuals with $\mathrm{AgCC}$ exhibit little evidence of a disconnection syndrome on interhemispheric transfer tests with simple tactile information (Lassonde et al. 1991). This suggests that neural plasticity in children may allow for reinforcement of alternative neural pathways for IHT.

Studies using tachistoscopically presented visual stimuli and studies of evoked potentials provide the most compelling information about functional interhemispheric connections in $\mathrm{AgCC}$ at various stages of sensory processing. As illustrated by visual evoked potentials, there is a complete lack of IHT at the level of early visual processing in $\mathrm{AgCC}$ (Brown et al. 1999), similar to what is seen in callosotomy patients. Despite this sensory disconnection, when comparing simple visual stimuli such as letters and colors across visual fields or coordinating simple bimanual tasks, $\mathrm{AgCC}$ patients have better interhemispheric integration of visual and tactile information than adult commissurotomy patients (e.g., (Brown et al. 1999; Brown et al. 2001; Jeeves and Silver 1988). This confirms that information can be transferred between the hemispheres in $\mathrm{AgCC}$, perhaps via other connecting pathways such as the anterior commissure.

However, the capacity for IHT in AgCC appears to be limited by task complexity. For example, in an across visual field matching task, performance was significantly less accurate when comparing more visually complex, less familiar, and less easily verbalized stimuli (Brown et al. 1999). Similar limitations in IHT in AgCC patients were evident on other tasks that required transfer or integration of the products of more complex cognitive operations required more rapid processing and relied on less prior experience (Brown et al. 2001; Jeeves et al. 1979; Meerwaldt 1983; Sauerwein and Lassonde 1983). Taken together, these studies indicate that compensatory pathways for IHT in AgCC are limited, resulting in a fairly consistent pattern of impairment in complex behaviors that rely upon rapid information processing between hemispheres such as problem solving, nonliteral language, and social communication. 
AgCC does not appear to have a direct or dramatic impact on general cognitive ability. IQ scores scores frequently remain within the average range, even though full-scale IQ may be lower than expected based on family history and there is an unusual tendency for significant discrepancy between performance IQ and verbal IQ (in either direction) (Chiarello 1980; Sauerwein et al. 1994). Likewise, AgCC does not appear to have a significant negative impact on general language skills such as naming (e.g., naming objects from line drawings (Liederman et al. 1985; Temple et al. 1989), receptive language (e.g., comprehension of sentences (Temple et al. 1989; Sauerwein et al. 1994), or lexical reading skills (Temple et al. 1990). However, it may result in impairments on more sophisticated language tasks.

Among individuals with AgCC and normal range IQ, linguistic impairments and social impairments are common. Deficits are evident in comprehension of syntax and linguistic pragmatics (including idioms, proverbs and vocal prosody) (Banich and Brown 2000; Sanders 1989; Brown et al. 2005b; Paul et al. 2003), and in phonological processing and rhyming (Banich and Brown 2000; Temple et al. 1989; Temple and Ilsley 1993; Sanders 1989). There is also evidence of poor comprehension of humor and nonliteral language forms, particularly due to difficulties in over-riding literal interpretation bias and using context to infer meaning (Paul et al. 2003; Brown et al. 2005a; Huber-Okrainec et al. 2005). The latter difficulties are also evident in poor conversation skills and restricted verbal expression of emotional experience (similar to alexithymia) (Buchanan et al. 1980; O'Brien et al. 1994). Parents of AgCC patients report a pattern of "meaningless" or "out-of-place" conversation as particularly common (O'Brien et al. 1994).

It is possible that these language deficits are a direct result of impaired coordination of the dual language pathways. According to the dynamic dual pathway model of language, syntax, and semantics are lateralized to the left hemisphere and prosody to the right hemisphere (Eckstein and Friederici 2006; Tabibnia and Zaidel 2005; Eckstein and Friederici 2005; Friederici and Alter 2004; Borod et al. 2002; Josse and Tzourio-Mazoyer 2004). In this model, the corpus callosum is critical for coordination of this lateralized information and callosal absence would result in particular deficits in processing syntactic and prosodic information (Eckstein and Friederici 2006; Eckstein and Friederici 2005; Friederici and Alter 2004), the very areas of linguistic weakness evident in AgCC.

It is also possible that the social deficits in $\mathrm{AgCC}$ result from broader deficits in information integration and processing speed. Data from large sample sizes suggest that problem solving abilities become more impaired as task complexity increases (Symington et al. 2010) and that processing speed is the principle cause of poor executive performance on standardized tests (Brown and Paul, unpublished observations). Impairments in abstract reasoning (Brown and Sainsbury 2000; David et al. 1993), problem solving (Aalto et al. 2002; Fischer et al. 1992; Imamura et al. 1994), generalization (the ability to extrapolate from one case to others) (Solursh et al. 1965), and category fluency (the ability to list multiple items that belong to a semantic category, e.g., names of animals) (David et al. 1993) have all been consistently observed in individuals with $\mathrm{AgCC}$. These executive functioning and problem solving deficits may result in diminished social self-awareness (Brown and Paul 2000) as well as difficulty imagining the social perspective of others (Symington et al. 2010; Turk et al. 2010).

Taken together, the neuropsychological findings in Primary AgCC highlight a pattern of deficits in problem solving, processing speed, and the social pragmatics of language and communication, which may result in significant complications of daily life. Parents report that children with $\mathrm{AgCC}$ and intact early motor development (i.e., sitting and walking within normal age range) are significantly likely to display clinically relevant behavior problems by the 6- to 11-year-old age range (Badaruddin et al. 2007). These include exhibit somatic complaints, attention problems, agressive behavior, social problems and thought problems. The frequency of psychiatric diagnoses in AgCC is unknown, however diagnosis of learning disabilities, developmental delays and/or psychiatric disorders appear to be common (Brown and Paul, unpublished observations). The social impairments in AgCC are remarkably similar to those seen on the autism spectrum. In a sample of sixty-one 2- to 11-year-old children with $\mathrm{AgCC}, 34 \%$ of the sample met criteria for at least one item in the social interaction domain (with maximum of $46 \%$ who had impaired peer relationships). In the communication domain, at least $30 \%$ met on one item (with a maximum of 51 who had difficulty sustaining conversation). Engaging in routines and $28 \%$ engaging in a specific interest. Further research should examine the patterns of autism spectrum type behavior in AgCC.

Callosal involvement in genetic conditions

\section{Neurofibromatosis1 (or von Recklinghausen disease)}

Neurofibromatosis1 (NF1) involves a chromosome 17q11.2 mutation that is transmitted in autosomal dominant fashion, although $50 \%$ of reported cases are caused by spontaneous mutations (Friedman and Birch 1997). Approximately 30$50 \%$ of patients with NF1 have cognitive deficits and/or learning disabilities, including specific impairments in visual-spatial skills, visuo-perception, executive dysfunc- 
tion, and motor coordination (North et al. 1997; Brewer et al. 1997; Cutting et al. 2000a; Cutting et al. 2000b; Ozonoff 1999).

The NF1 gene product, neurofibromin, is expressed early in fetal development and is likely to aid in differentiation of CNS neurons (North 2000). Neuroanatomic studies of NF1 patients are characterized by widely distributed areas of increased signal intensity on MRI (UBOs; (Truhan and Filipek 1993)), as well as macrocephaly involving both gray and white matter (e.g., (Moore et al. 2000; Cutting et al. 2002; Margariti et al. 2007; Greenwood et al. 2005; Steen et al. 2001) and enlarged CC area (Kayl et al. 2000; Margariti et al. 2007; Dubovsky et al. 2001) relative to controls. The rostral body, anterior midbody, and posterior midbody were significantly larger in NF1 than controls (Kayl et al. 2000). dMRI in adults with NF1 has revealed bilateral reductions in FA and increases in ADC of the caudate, lentiform nucleus, thalamus, frontal white matter, parietoccipital white matter, and the corpus callosum (Zamboni et al. 2007). While this indicates that NF1 probably involves reduced efficiency of callosal connections, that reduction should be interpreted within the larger context of global reductions in white matter connectivity.

Patients with NF1 have an atypical disassociation of gray matter volume and IQ (Greenwood et al. 2005), suggesting that the cortical overgrowth in NF1 is not cognitively useful. This is corroborated by positive correlations between gray matter volume and learning disabilities in NF1, as well as correlations between callosal enlargement and cognitive impairments on academic, visuospatial and motor tests (Moore et al. 2000). Although comparison children with NF1-only and NF1 plus attention-deficit hyperactive disorder (ADHD) did not differ in callosal size, there was an overall positive correlation of attentional performance and callosal area in these groups (Kayl et al. 2000). In sum, callosal enlargement in NF1 appears to contribute to impairments in academic skills, motor coordination, or visuospatial skills, but may facilitate attention. It is possible that callosal overgrowth in NF1 actually reduces the developmental drive toward hemispheric specialization in this group.

\section{Turner syndrome}

Women with Turner syndrome (TS) are born with only one $\mathrm{X}$ chromosome, which results in a characteristic physical and cognitive phenotype (Lawrence et al. 2003b; Collaer et al. 2002; Murphy et al. 1994; Ross et al. 2002; Ross et al. 2000). Most women with TS have intact general intelligence (Van Dyke et al. 1991), with a pattern of specific deficits in mathematics, visuospatial processing, visuomotor control, and executive function (Reiss et al. 1995b;
Romans et al. 1998; Ross et al. 2000). There is evidence that this profile of cognitive impairments is consistent between pre-pubescent girls with TS and adult women with TS who have adequate estrogen effects, indicating that the cognitive profile is not estrogen-related (Ross et al. 2002). Women with TS also demonstrate significant social impairments, difficulty interpreting paralinguistic cues, and poor self-concept (Downey et al. 1989; McCauley et al. 1987; McCauley et al. 1995; Skuse et al. 1997). Laboratory experiments have revealed impaired face recognition and impaired recognition of fear expressions (Ross et al. 1995; Ross et al. 1997), particularly when judging emotion from eyes (Lawrence et al. 2003a). Correlation of behavioral ratings with neural and psychophysiological measures (functional magnetic resonance imaging (fMRI) and SCR) in TS revealed a pattern of intact emotional responses in the amygdala and arousal systems and a positive correlation between performance on emotion naming and the extent of functional connection between left amygdala and left fusiform gyrus (Skuse et al. 2005). This suggests that social processing deficits in TS may be a direct consequence of functional disconnection between cortical areas involved in specific social tasks.

Consistent with these cognitive deficits, there is substantial evidence of size reduction and atypical functionality in the parietal and occipital cortices of women with TS (Cutter et al. 2006; Reiss et al. 1995b; Clark et al. 1990). Callosal involvement in TS is supported by several published case studies of callosal dysgenesis (Kimura et al. 1990; Abd et al. 1997; Araki et al. 1987; Hori 1996), as well as group analyses of callosal morphology (Fryer et al. 2003; Cutter et al. 2006). However, the group studies provide somewhat contradictory findings. Whereas an adolescent TS sample (mean age $=13 \pm 4$ years) had reduced genu area relative to age-matched controls (Fryer et al. 2003), an adult TS sample (mean age $=27 \pm 8$ years) exhibited reduced splenial area and enlargement of the genu (in addition to reduced white matter volume in the parieto-occipital regions and increased white matter volume in the temporal and orbitofrontal lobes (Cutter et al. 2006).

Taken together, these findings suggest that white matter reductions in TS shift from anterior to posterior through the transition from child to adult, resulting in enlargement of the anterior callosum, as well as temporal and orbitofrontal white matter. As noted earlier, the cognitive profile in TS does not change through adolescence, suggesting that the white matter changes may be either unrelated to cognitive deficits or may reflect a shift in cognitive processing circuits perhaps to accomodate for hormone-related changes. If this developmental pattern is confirmed by future longitudinal studies in TS, it may provide important evidence regarding the impact of hormone changes on white matter pathways. 


\section{$22 q 11.2$ deletion syndrome}

The 22q11.2 deletion syndrome (22qDS; also called velocardiofacial/ DiGeorge syndrome) results from a hemizygous deletion at chromosome 22q11.2 (Stachon et al. 2007). In addition to atypical facial morphometry and multiple medical complications (McDonald-McGinn et al. 1999; McDonald-McGinn et al. 1997), individuals with 22qDS typically demonstrate relatively stronger language than visuospatial skills (Wang et al. 2000). Specific deficits in visuospatial cognition, arithmetic (Wang et al. 2000; Bearden et al. 2001; Moss et al. 1999; Swillen et al. 1997), and spatial attentional orienting (Simon et al. 2005) are common. There is also a high incidence of psychopathology in this population, including attention-deficit hyperactivity disorder (Antshel et al. 2005; Niklasson et al. 2001; Gothelf et al. 2007), obsessive-compulsive disorder (Gothelf et al. 2004), autistic spectrum disorder (Fine et al. 2005; Niklasson et al. 2001; Antshel et al. 2007; Kates et al. 2007); schizophrenia (Murphy 2002), and bipolar disorder (Arnold et al. 2001; Papolos et al. 1996).

Individuals with $22 \mathrm{qDS}$ tend to have smaller brains than controls, with slightly greater reduction in white matter than gray matter (Eliez et al. 2000; Kates et al. 2001). Children with 22qDS appear to have cortical thinning of the anterior cingulate cortex, portions of medial frontal gyrus, subgenual prefrontal cortex, and inferior-posterior regions (including posterior cingulate gyrus, lingual gyrus, and cuneus; (Bearden et al. 2009)). Cortical thinning in that sample was most pronounced in the right ventromedial occipital-temporal cortex. There is also evidence for hemispheric asymmetry (left smaller than right) of the temporal lobe (van Amelsvoort et al. 2001) and parietal cortex (Eliez et al. 2000). These cortical gray matter volume deficits (particularly in frontal lobes) correlated directly with both verbal and nonverbal IQ in children with 22qDS (a similar correlation was not found in matched controls; (Bearden et al. 2009)). Relative to age-matched peers (without accounting for IQ), young people with $22 \mathrm{qDS}$ had significant bilateral white matter volume reductions in parts of the cerebellum and brainstem, cuneus and precuneus, posterior thalamic radiation, genu, and areas of callosal body, hippocampus, paracentral lobule, optic radiation and lingual, middle and inferior occipital gyri. In contrast, (also without accounting for IQ) they had elevated bilateral white matter volume in the anterior internal capsule, tracts from the basal ganglia, medial frontal gyrus and cingulum, splenium, and areas of the callosal body (Sundram et al. 2010). However, when IQ was covaried, overall white matter volume was significantly higher in the 22qDS subjects than controls.

Studies have generally agreed that total callosal area is enlarged in 22qDS, but have differed with respect to size variations among callosal regions (Machado et al. 2007; van Amelsvoort et al. 2001; Shashi et al. 2004) and often did not take IQ variations into account. This variability in callosal morphology results may be due, at least in part, to the atypical shape of the callosum in 22qDS. Using nonrigid registration of the callosum and a highly refined partitioning method, a recent study of children with 22qDS found that they mainly differed from controls with regard to the shape and size of anterior CC (Machado et al. 2007). Specifically, in 22qDS the rostrum was longer and larger, and the rostrum and rostral body were more curved. In contrast, the controls exhibited greater width and more curvature of the genu. Although this study did not find group differences in splenium structure, splenial enlargement was reported in one study of adults with 22qDS (van Amelsvoort et al. 2001).

In the aforementioned sample of children with $22 \mathrm{qDS}$, genu area was positively correlated with faster performance on enumeration, and to a lesser degree on subitizing. In contrast, rostral body and midbody area were negatively correlated with faster performance on enumeration and area of isolated segments in the posterior midbody and splenium were negatively correlated with faster subitizing performance. Control subjects did not exhibit correlations between enumeration or subitizing performance and callosal area measures. This suggests that for individuals with 22qDS, visuospatial attention and numerical cognitive processing depends more heavily on anterior interhemispheric networks than is commonly seen in controls, and that enhanced midbody and splenial connectivity may actually impede performance (Machado et al. 2007).

As discussed earlier, area measures are likely to reflect axon density in the genu and to a lesser extent in the rostral body. These callosal regions connect prefrontal association areas (Hofer and Frahm 2006) and anterior inferior parietal regions (de Lacoste et al. 1985), areas involved in enumeration. Evolutionary biology suggests that reduced callosal size requires greater hemispheric specialization. In 22qDS, we may be seeing the opposite pattern-i.e., the reduction in parietal white matter direclty correlates with reduced cognitive specialization, resulting in greater dependence on callosal connections for the tasks that typically depend upon localized parietal activity. To test this hypothesis, future studies could examine intra-individual correlations of parietal white matter volume and genu area within the 22qDS group.

Diffusion imaging studies have reported descrepant findings in 22qDS. One study of 19 individuals aged 722 years reported elevated FA values in the splenium (Barnea-Goraly et al. 2003), but did not covary group differences in IQ. A smaller study of 11 individuals with 22qDS aged 9-17 years reported reduced FA of the splenium and right callosal body when controlling for IQ 
(Sundram et al. 2010). In that sample of individuals with 22qDS group, FA of the right callosal body and left splenium were negatively correlated with elevated schizotypy scores. Additionally, subjects with each the Val allele polymorphism of the catechol- $O$-methyltransferase (COMT) gene had lower FA values in the frontal lobes, cingulum and corpus callosum than the subjects who had the Met variant of COMT (Sundram et al. 2010). These findings indicate that in $22 \mathrm{qDS}$ white matter structure interacts with IQ and that reductions in callosal FA are related to the factors causing schizotypy and the Val allel variant of COMT.

Another potential cause of variability in CC morphology results across studies is presence of comorbid ADHD. A sample of children with 22qDS had larger overall callosal area than controls, as well as larger area measures for all regions except the genu. When divided into two subgroups, 22qDS alone and 22qDS plus ADHD, both groups retained the same pattern of callosal area findings relative to controls. However, the 22qDS plus ADHD group had significantly smaller total callosal area, as well as smaller genu and splenium areas, relative to the 22qDS only group. This suggests that the neural symptoms of comorbid ADHD mitigate the impact of $22 \mathrm{qDS}$ on the callosum (Antshel et al. 2005).

\section{Williams syndrome}

Williams syndrome (WS) is a neurogenetic disorder caused by a microdeletion of one copy of genes on chromosome $7 \mathrm{q} 11.23$, including genes that are crucial for neuronal migration and maturation. It is commonly characterized by distinct facial morphometry, hypersociability, developmental delay, select language deficits, deficits in visuospatial skills, and hyperactivity. Individuals with WS typically have mild to moderate intellectual impairment with relative cognitive strengths in language skills such as syntax, semantics, and vocabulary and strong predilection for auditory stimuli, especially music (for review of behavioral phenotype see (Martens et al. 2008)).

Morphological studies indicate that overall brain size is reduced in WS (Jernigan et al. 1993; Chiang et al. 2007), with greater reduction in white matter than gray matter volume (Reiss et al. 2000), greater reductions in posterior regions than anterior regions (Chiang et al. 2007), and reduced hemispheric asymmetry of posterior regions (Gaser et al. 2006; Sampaio et al. 2008). Specifically, volume was reduced in the parietal and occipital lobes, thalamus, basal ganglia and midbrain, and preserved volume in the frontal lobes, anterior cingulate, superior temporal gyrus, amygdala, fusiform, and cerebellum (Chiang et al. 2007). There is also evidence of atypical hemsipheric asymmetry, particularly in posterior regions. WS subjects exhibiting areas of increased leftward gyrification asymmetry across the medial surface, as well as bilaterally increased gyrification of occipital lobes (Gaser et al. 2006). With regard to cortical volume, WS subjects had reduced leftward asymmetry of posterior regions that are typically highly asymmetric, including the superior temporal gyrus (STG; (Sampaio et al. 2008)). There is also evidence of atypical functional asymmetry in WS. At the cellular level, visual-spatial deficits that typically emerge from right hemisphere damage appear to primarily involve the left hemisphere in WS (Galaburda et al. 2002). Likewise, dichotic listening performance also indicates that WS subjects have an atypical bias toward processing negative affect in the left hemisphere (Jarvinen-Pasley et al. 2010). Finally, in WS subjects left STG volume and verbal intelligence scores were not correlated, as is typically found in controls (Sampaio et al. 2008). These findings of reduced parietal and occipital volume and atypical hemispheric lateralization are consistent with morphological patterns of the CC in WS.

Although callosal absence is not a common symptom of Williams syndrome, some degree of callosal dysgenesis, and under-development of the anterior commissure have been reported, as well as increases in intrahemispheric connections (Marenco et al. 2007; Hofer et al. 2007). Multiple studies have examined callosal morphology in $\mathrm{WS}$, revealing that the $\mathrm{CC}$ is abnormally shaped/less concave (Luders et al. 2007; Tomaiuolo et al. 2002; Gothelf et al. 2008), that it is smaller or shorter than typical (Luders et al. 2007; Tomaiuolo et al. 2002; Schmitt et al. 2001), and that the posterior regions, including the isthmus and splenium, are particularly smaller (Luders et al. 2007; Tomaiuolo et al. 2002; Schmitt et al. 2001). There is also evidence of reduced area in the caudal region of the callosal body (Tomaiuolo et al. 2002).

Behavioral studies suggest that there may be subtle limitations of interhemispheric connectivity in WS, with elevation in intrahemispheric connections. Patients with WS performed similarly to controls on a bilateral-visualfield matching (bilateral field advantage and a left hemisphere advantage on unilateral presentations), but unlike controls, performance of the WS patients did not improve with age (Santos et al. 2007). This indicates that reduced area of the posterior callosum in WS may limit adult-level interhemispheric transmission. In contrast, increased intrahemispheric connectivity (i.e., elevated anisotropy) within right superior longitudinal fasciculus was negatively correlated with the visuospatial performance in WS patients (Hoeft et al. 2007).

The migrational disruption in WS appears to impede development of $U$ fibers and/or longitudinal long-range connections during later stages of fetal development (Marenco et al. 2007). It is likely that $U$ fibers which were intended for intrahemispheric connection are redirected longitudinally, 
resulting in alterations of intrahemispheric fiber bundles (Hoeft et al. 2007; Chiang et al. 2007), reduced hemispheric asymmetry (Sampaio et al. 2008; Gaser et al. 2006), and development of additional aberrant intrahemispheric bundles (Marenco et al. 2007). These cortical malformations in posterior regions are also evident in reduced area of posterior $\mathrm{CC}$ and in atypical involvement of the left hemisphere in cognitive functions that are typically lateralized in the right (Galaburda et al. 2002, Jarvinen-Pasley et al. 2010).

\section{Fragile $X$}

Fragile $\mathrm{X}$ syndrome, is an inherited, $\mathrm{X}$-linked disorder caused by a specific single-gene mutation (Tamanini et al. 1996). In females, the syndrome typically involves mild cognitive impairment and learning deficits, as well as poor socialization, elevated anxiety and poor attention. Males are likely to have moderate to severe mental retardation. In males, IQ may decline during childhood (Hodapp et al. 1990) and does not correlate normally with volumetric brain measures (Eliez et al. 2001). Males with fragile X may also exhibit specific deficits in executive function, visuospatial skills, and visuomotor coordination (Hodapp et al. 1990).

Autism-like social deficits are evident in over 30\% of males with fragile X (Baumgardner et al. 1995; Freund et al. 1992; Mazzocco et al. 1997; Reiss et al. 1995a) and in pre-mutation carriers of the fragile $\mathrm{X}$ gene (Dorn et al. 1994; Moore et al. 2004). In the latter group, these social deficits were associated with reduced amygdala activitywhen viewing fearful faces (Hessl et al. 2007). Their pattern of reduced amygdala, orbitofrontal cortex and superior temporal sulcus activation suggests that those areas may be causally related to the social deficits seen in fragile X. Notably, these areas have also been implicated in causal theories of autism (Pelphrey et al. 2005).

The gene mutation in Fragile $\mathrm{X}$ alters brain development by reducing transcription and translation of the FMRP protein (Tamanini et al. 1996). Ultimately, this leads to alterations in dendritic arborization and gray matter enlargement (Irwin et al. 2000; Willemsen et al. 2004; Beckel-Mitchener and Greenough 2004; Galvez and Greenough 2005). Although there is no evidence of CC abnormality in fragile $\mathrm{X}$, there is a pattern of select volume increases in periventricular white matter, with a trend toward elevated parietal and temporal white matter volumes in fragile $X$ versus controls (Lee et al. 2007).

Callosal outcome of prenatal incidents

\section{Low birth weight and preterm infants}

Children born significantly preterm ( $\leq 33$ weeks) often exhibit behaviors such as withdrawal, thought disorganization, attention problems, aggression, and social problems (Nagy et al. 2003; Hoy et al. 1992; Sykes et al. 1997). Diffuse white matter damage is the most common neural abnormality evident on MRIs of preterm infants (Stewart et al. 1999; Maalouf et al. 1999) and may be associated with regional volume reductions (Boardman et al. 2006) and developmental impairment (Dyet et al. 2006).

Neurodevelopmental impairments in infants born preterm appear to be related to CC size (Nosarti et al. 2004; Peterson et al. 2000; Rademaker et al. 2004), as well as regionally specific microstructural callosal abnormalities (Counsell et al. 2008a). Specifically, reductions in callosal area are most evident in the posterior body of preterm infants (Counsell et al. 2008a; Peterson et al. 2000; Rademaker et al. 2004; Cooke and Abernethy 1999; Stewart et al. 1999). Although regional CC size and microstructure may vary somewhat by gestational age at birth, callosal abnormalities typically persist into adolescence (Nagy et al. 2003), and have long-term consequences on behavior (Nosarti et al. 2004; Counsell et al. 2008a; Anderson et al. 2005; Anderson et al. 2006; Peterson et al. 2000; Rademaker et al. 2004).

In children born preterm, $\mathrm{CC}$ length at term equivalence is positively correlated with developmental outcome, regardless of the actual age at birth. Preterm infants born prior to 33 weeks gestation exhibit normal $\mathrm{CC}$ growth during the first two weeks of life, but from that time until term equivalent the $\mathrm{CC}$ growth rate diminishes to less than half of the expected rate for antenatal CC growth. Although some infants born after 28PCW exhibit improved CC growth rates after 6 weeks of age, the reduced growth between 2 to 6 weeks is directly correlated with serious motor delays and cerebral palsy by age 2 years. Taken together, these findings suggest that neuroprotective strategies may be most effective when administered immediately after birth (Anderson et al. 2005; Anderson et al. 2006), but are unlikely to provide complete recovery of callosal structure.

The relationship of CC area and behavior continues into childhood and adolescence. A sample of 8-year olds born preterm found significant size reductions in the total $\mathrm{CC}$, as well as all subregions (both with and without adjusting for total brain volume). Five-minute APGAR score correlated positively with size of the CC midbody (Peterson et al. 2000). By adolescence, total CC area adjusted for total white matter volume was $~ 7.5 \%$ smaller in $14-15$-year olds born at $\leq 33$ weeks than in controls. When controlling for total mid-sagittal CC area, the posterior quarter of the CC was $7.9 \%$ smaller than controls and the anterior quarter was $8.3 \%$ larger than controls. In every preterm boys, total midsagittal CC area and the mid-posterior quarter area correlated positively with verbal IQ and verbal fluency (Nosarti et al. 2004). Other studies have found that CC size after preterm birth is positively correlated with verbal and 
performance IQ (Peterson et al. 2000), motor function (Rademaker et al. 2004), and visual-motor integration (Peterson et al. 2000; Rademaker et al. 2004), all of which are consistent with indications that posterior callosal area is positively correlated with volume of the related projection areas (sensorimotor, midtemporal, and occipital (Peterson et al. 2000).

Neurodevelopmental impairments in infants born preterm also appear to be related to microstructural abnormalities in specific regions of the corpus callosum (Counsell et al. 2008a). Around term-corrected age, microstructure in brains of preterm infants is less directionally specific on average than their term-born peers (i.e., lower FA values; (Huppi et al. 1998; Neil et al. 1998; Miller et al. 2002; Counsell et al. 2006), with most marked reductions of FA in the genu (Anjari et al. 2007). In infants born before 28 PCW, genu FA was even more significantly reduced and reduced FA was evident in the callosal body and isthmus (Anjari et al. 2007). Preterm infants with diffuse excessive high signal intensity on MRI exhibited significantly elevated diffusion coefficients in the splenium (Counsell et al. 2006).

In preterm infants tested at 2 years of age, FA values in the isthmus and body were significantly positively correlated with developmental quotient scores, performance subscores, and eye-hand coordination (Counsell et al. 2008a). Microstructural abnormalities of the posterior $\mathrm{CC}$ have also been identified in 11-year olds born very preterm. Coherence analysis comparing anisotropy of nearest neighbors indicated that the neural fibers of this region were well organized. Therefore, they concluded that decreased anisotropy is likely to be related to one or the combination of (1) reduced axon diameter, (2) fewer axons, and (3) poorer myelination (Nagy et al. 2003).

By adolescence, preterm infants with isolated callosal damage demonstrated general processing speed deficits, as well as specific response time deficits related to reduced callosal transfer. fMRI studies conducted during callosally mediated visual and auditory tasks revealed sensory-specific recruitment of compensatory neural systems in response to prenatal callosal damage. For example, relative to preterm subjects without callosal damage and normal-term control subjects, a sample of preterm subjects with callosal damage demonstrated intact accuracy on bilateral matching across visual fields indicating capacity for callosal transfer, significant slowing on both the within and between visual-field conditions indicating a general impairment in processing speed, and finally a bilateral field disadvantage indicative of reduced callosal transfer (Santhouse et al. 2002). fMRI results indicated that control subjects did not have any regions of greater activation when matching across visual fields than within. However, the callosal damage group exhibited additional activation of dorsolateral prefrontal cortex during visual field comparisons, which suggests that they may be recruiting this region (i.e., working memory) to help compensate for diminished callosal transfer.

\section{Fetal alcohol syndrome}

Fetal alcohol syndrome (FAS) and fetal alcohol spectrum disorders (FASD) (Jones and Smith 1973; Lemoine et al. 1968) consist of a distinct pattern of birth defects caused by in utero alcohol exposure. The main features of FAS include growth retardation (pre- and postnatal), central nervous system dysfunction, and a characteristic pattern of atypical facial morphometry. The term FASD is given to individuals with heavy prenatal exposure to alcohol, but without the characteristic facial morphometry of FAS. FASD commonly involves cognitive and psychosocial abnormalities consistent with FAS, including slowed information processing and impaired executive control (Sowell et al. 2001; Mattson and Riley 1998; Mattson et al. 1998; O'Hare et al. 2005). Individuals with FASD also exhibit greater impairment with increased task complexity, in both verbal and nonverbal domains (for review see (Kodituwakku 2007).

Callosal malformation is common in FASD. Incidence of callosal agenesis is reportedly $6.8 \%$ in FAS, which is much higher than the incidence in the general population ( $\sim 0.025 \%$, (Roebuck et al. 1998)). Among the remainder of the FAS population, area reductions of anterior and posterior callosal regions is common (Riley et al. 1995; Sowell et al. 2001), as well as displacement of the posterior callosal regions to more anterior and inferior positions (Sowell et al. 2001). In adolescents with FASD, there is evidence of reduced FA in the CC overall (Sowell et al. 2008), specifically in posterior midbody and isthmus (Wozniak et al. 2009) and the splenium (Sowell et al. 2008; Wozniak et al. 2009).

There are several lines of evidence regarding impaired interhemispheric transfer in FASD. On a bimanual coordination task that utilizes callosal connections between motor cortices, children with FASD performed more slowly than matched controls, but with equal accuracy. As demand for interhemispheric coordination increased, performance of the FASD group became more variable and inaccurate (RoebuckSpencer et al. 2004). There is also evidence that white matter integrity of posterior $\mathrm{CC}$ is positively correlated with visualmotor integration performance but not with reading scores in FASD groups (Sowell et al. 2008; Wozniak et al. 2009). However, white matter density measures did not correlate with visual-motor integration or reading in FASD (Sowell et al. 2008).

Taken together these findings suggest that the posterior CC may be particularly vulnerable to prenatal alcohol effects and that the structural changes of that area have a select negative impact on visual-motor integration and bimanual coordination. 
Callosal involvement in behavioral developmental diagnoses (Bishop 1994)

\section{Developmental language disorder}

Developmental language disorder (DLD; also called specific language impairment) encompasses a range of developmental disabilities involving impaired linguistic abilities in the absence of obvious neurological damage, hearing deficits, mental retardation, or severe environmental deprivation (Bishop 1992). The phonologic-syntactic subtype is most common. It includes both receptive and expressive deficits, such that these children may be nonverbal or have very limited, possibly unintelligible speech. Other subtypes of DLD include expressive disorders such as verbal dyspraxia (which may occur with intact comprehension) and higherorder processing disorders involving impairments in semantics and pragmatics of social discourse (Rapin 1996).

Various theories have been proposed regarding the underlying deficit in DLD. One theory suggests that at least some subtypes of DLD result from specific language deficits such as grammar (for example, (Clahsen 1989; Rice and Oetting 1993; Ullman and Gopnik 1994). Other theories maintain that DLD is the consequence of a more general processing impairment such as a deficit in temporal auditory processing (Merzenich et al. 1993; Tallal et al. 1993), broadly reduced processing speed (Kail 1994; Bishop 1994) or deficits in the systems that learn and execute motor and cognitive skills (i.e., procedural memory systems, (Ullman and Pierpont 2005). If these theories represent subtypes of DLD, then it is likely that those that involve language-specific deficits and/or deficits in procedural memory will have structural involvement of frontal areas (particularly left frontal inferior cortex) and those that involve broader deficits in processing speed may exhibit structural deficits in posterior areas such as the superior temporal gyrus (specifically the planum temporale; (Friederici 2006) or a broader pattern of impaired white matter connectivity including the corpus callosum.

Neuroanatomic studies in children with DLD reveal unusual patterns of cortical asymmetry. Globally, hemispheric and lobar volume is less asymmetric in individuals with DLD compared with controls, but volumetric analysis of functionally-specific cortical regions revealed that DLD involves more significantly asymmetric regions (Herbert et al. 2005). Out of 48 cortical bilateral regions, 15 regions were significantly asymmetrical in the DLD group (32.6\% of cortical volume) whereas only eight were significant in controls $(20.1 \%$ of cortical volume). This group difference was primarily explained by temporal lobe asymmetries: DLD had eight more asymmetric regions than controls. In the other lobes, the groups only differed by one significantly asymmetric region per lobe. Relative to controls, some language structures in the DLD group were less asymmetric (pars triangularis, frontal operculum, angular gyrus), and others were more asymmetric to the right (planum polare, posterior supramarginal gyrus) or the left (planum temporale, anterior supramarginal gyrus, posterior inferior temporal gyrus, temporal pole, posterior temporal fusiform). While individuals with DLD have sigificantly greater total volume of right-asymmetric regions and significantly reduced total volume of left-asymmetric regions relative to controls, the group difference is smaller for left-lateralized regions than for right-lateralized regions, resulting in aggregate decrease of lateralized cortical volume in DLD (i.e., the combination of a small reduction in left-lateralization and a larger increase in right-lateralization results in an overall decrease of lateralized area; (Herbert et al. 2005). Essentially, analysis of larger units (hemispheres or lobes) masks the increased asymmetry found for DLD subjects at the regional-level.

Across species, increased cerebral lateralization in humans is associated with decreased interhemispheric connectivity (a decrease in both fiber numbers and an increase in interhemispheric transmission delay; (Olivares et al. 2000; Olivares et al. 2001; Witelson 1989; Aboitiz 1992; Aboitiz et al. 1992a; Aboitiz et al. 1992b; Witelson 1985; Dorion et al. 2000). Thus, increased hemispheric asymmetry in DLD is consistent with the finding that in DLD the volume of frontal, temporal, and occipital radiate white matter is increased, while volume of deep white matter is retained (Herbert et al. 2004; Leonard et al. 2006). Children with DLD do not exhibit abnormalities in absolute area of the total CC, CC subareas, or the ratio of subarea to total (Preis et al. 2000). However, they tend to have a smaller splenium relative to the entire $\mathrm{CC}$ area, as might be expected given that increased asymmetry was greatest in temporal cortex of DLD group (Herbert et al. 2005). One study documented reduced FA in the genu of children ages 2.5 to 6.5 years with DLD (Kim et al. 2006) and suggested that their finding may reflect a delay in CC development. These findings suggest that cortical involvement in DLD does not significantly impact $\mathrm{CC}$ structure at a level that can be identified via gross morphology, and leave open the question of how developmental progression may impact the CC in DLD.

Behavioral studies of IHT have offered stronger evidence regarding callosal involvement in DLD. The initial suggestion of a causal relationship between callosal malformation and DLD was based on observations that many children with callosal abnormalities had language difficulties and that many children with DLD also had deficits in motor coordination (Njiokiktjien 1983; Njiokiktjien et al. 1988). Using a simple sensory-motor IHT test, 7-12-year olds with DLD (both receptive and expressive types) performed significantly worse on the IHT task than the within-hemisphere task, whereas controls' performance did not differ significantly 
between conditions (Fabbro et al. 2002). The DLD group performed similarly to controls on the same hand responses, but made significantly more errors than controls on opposite hand responses, indicating that the sensory-motor abnormalities observed in DLD are more likely to reflect callosal dysfunction than a general sensory-motor deficit.

The relationship between the CC and DLD does not seem to be obvious at the level of gross morphology. However, it is evident in behavioral studies that demonstrated impaired interhemispheric transfer of sensory information in this population. One theory suggests that language is particularly susceptible to white matter abnormalities because it is so highly reliant on associational processing (Mesulam 1998).

\section{Dyslexia}

Dyslexia involves a more significant deficit in reading decoding than reading comprehension (Conners and Olson 1990), which is essentially the opposite in DLD (Bishop and Adams 1990). Studies of cortical morphology suggest that callosal connections and auditory processing are more prominent in dyslexia than in DLD.

Morphology of the CC in dyslexia has garnered variable results, mostly likely due to confounds introduced by inclusion of dyslexic subjects with comorbid conditions. Among studies that excluded comorbid conditions, there is evidence of a positive relationship between reading skill and total CC area, as well as a positive relationship between oral reading skill and $\mathrm{CC}$ midbody area (relative to whole brain volume) (Fine et al. 2007). The callosal midbody is involved in processing primary sensory and higher level auditory info (Aboitiz 1992), as well as premotor and primary motor cortices (Hofer and Frahm 2006). Because the callosal midbody contains larger, less densely packed axons than other regions, variations in midline area are likely to reflect variations in axons size, not number. Large axons facilitate the rapid sensory integration needed to perceive temporal cues in auditory and visual stimuli. Therefore it is not surprising that poor readers generally have difficulty processing rapidly changing auditory and visual stimuli (Tallal et al. 1998; Stein 2001; Livingstone et al. 1991) and exhibit impairments in bimanual coordination (Moore et al. 1995). Among individuals with dyslexia, adults who have greater phonological processing deficits (Moore et al 1996) and children who tend to read quickly and inaccurately at least some of the time (i.e., "linguistic dyslexia" (Fabbro et al. 2001) have the most difficulty with interhemispheric transfer of complex tactile information. Within a dyslexia population, bimanual coordination performance was positively correlated with visuoconstruction performance (Moore et al. 1995), suggesting that effective callosal integration of visuospatial information may significantly impact reading skill.
While area of the callosal midbody is reduced in dyslexia, several studies have found enlargement of the splenium (Duara et al. 1991; Rumsey et al. 1996; Kilian et al. 2008). The anterior splenium consists of small, densely packed axons; therefore, splenial enlargement typically indicates a greater number of axons and stronger connectivity. dMRI studies of children with dyslexia have found that reading skills were negatively correlated with FA and positively correlated with RD in splenial areas connecting the temporal lobes (Dougherty et al. 2007; Odegard et al. 2009). In other words, temporal connections via the callosum are more directionally specific in poor readers, probably due to greater number of axons and more extracellular structure. Greater interhemispheric splenial connectivity in poor readers is consistent with the finding of greater perisylvian symmetry in dyslexia than in controls (Hynd et al. 1990; Kushch et al. 1993; Larsen et al. 1990). In contrast, larger and fewer temporal callosal fibers may allow good readers to simultaneously capitalize on cortical lateralization and very rapid interhemispheric integration.

\section{Attention-deficit hyperactive disorder}

Attention-deficit hyperactivity disorder is defined by various symptoms of inattention and/or hyperactivity-impulsivity. Theories regarding etiology of ADHD have focused on neural networks, particularly fronto-striatal-cerebellar connections (Durston 2003; Levy and Farrow 2001) and on frontal-limbic connections (Sowell et al. 2003; Mostofsky et al. 2002). Studies of the latter theory have illuminated abnormalities in hemispheric asymmetry (Hynd et al. 1990; Langleben et al. 2001), specifically reduced asymmetry of basal ganglia volume, with a rightward dominance of the caudate (e.g., (Castellanos et al. 1994)). In keeping with those findings, an early study of CC in children with dyslexia and comorbid ADHD reported significant size reduction in the genu and splenium (Hynd et al. 1995) (i.e., less laterality requires less interhemispheric connection). Subsequent studies have confirmed splenium reduction in children and adolescents with isolated ADHD (Valera et al. 2007; Hutchinson et al. 2008), with less consistency in findings regarding size of anterior callosum.

A meta-analysis of callosal morphology studies using mixed-gender samples with isolated ADHD confirmed that based on significance of effect sizes, reduced splenium size in ADHD is a reliable finding (Hutchinson et al. 2008). However, when ADHD samples consisted of only males, splenium size was not consistently impacted but rather, there was evidence of diminished rostral body size compared with controls (Hutchinson et al. 2008). Although data was not available for meta-analysis of only females with ADHD, the differences between male-only and mixed-gender ADHD samples suggest that splenium reduction is more pronounced 
in females with ADHD. It is possible that these gender differences in callosal morphology may correlate with diagnostic subtypes. For example, rostral body size was significantly negatively correlated with teacher/parent ratings of hyperactivity and impulsivity (Giedd et al. 1994) and the hyperactive subtype is more common in males. Whereas, reduction of parietal connections though the splenium may provide a potential neural substrate for impairments in sustained and divided attention (Hutchinson et al. 2008), both of which are core symptoms of the inattentive subtype more common in females.

Callosal involvement in ADHD is also supported by studies of transcallosally mediated motor inhibition and visual evoked potentials. Left to right transcallosally mediated motor inhibition is reduced in children with ADHD (Buchmann et al. 2003; Gilbert et al. 2004; Moll et al. 2000). Administration of methylphenidate improved motor inhibition in ADHD subjects without impacting motor threshold or motor evoked potentials (Buchmann et al. 2006; Moll et al. 2000). In conjunction with this slowed left to right transcallosally medicated motor inhibition, evidence in adults with hyperactivity/impulsivity symptoms (combined-type ADHD) indicates that they have faster left to right transfer of visual evoked potentials than controls (Rolfe et al. 2007). The combination of fast transmission of excitatory primary sensory information with slowed interhemispheric motor inhibition provides an intriguing explanation for behavioral impulsivity in ADHD. In contrast, adults with inattentivetype ADHD exhibited significantly slower right to left transfer of visual evoked potentials than controls (Rolfe et al. 2007).

These examples highlight the need for diagnostic accuracy in studying ADHD, as well as in studies of other conditions that are commonly comorbid with ADHD. In several clinical populations callosal size was compared in those subjects with and without comorbid ADHD (e.g., dyslexia, NF-1, and 22qDS). Across conditions, the findings indicate that subjects with comorbid ADHD are likely to have diminished callosal size, but typically not to an extreme that changes the pattern of callosal size differences for that diagnosis relative to controls (Kayl et al. 2000; Antshel et al. 2005; Hynd et al. 1995).

\section{Autism}

Autism is a complex behavioral diagnosis that includes deficits in communication and social interaction, as well as patterns of restricted and repetitive behaviors. The hypoconnectivity theory of autism proposes that autism results from disrupted long-range connectivity throughout the brain. Callosal involvement in autism is supported by evidence of reduced CC cross-sectional volume (total and all regions) (Alexander et al. 2007; Boger-Megiddo et al. 2006; Egaas et al. 1995; Manes et al. 1999) and reduced FA of fibers throughout the callosum (Alexander et al. 2007). However, results regarding structural variations in $\mathrm{CC}$ regions have not been consistent. Reduced cross-sectional area and volume have been identified in anterior (Manes et al. 1999; Kilian et al. 2008; Hardan et al. 2000; Chung et al. 2004; Vidal et al. 2006; Just et al. 2007), midbody (Kilian et al. 2008; Piven et al. 1997; Manes et al. 1999), and posterior regions (Piven et al. 1997; Egaas et al. 1995; Haas et al. 1996; Waiter et al. 2005; Vidal et al. 2006; Just et al. 2007).

Similarly, diffusion MRI results in autism have varied by region, including reports of reduced FA in the genu (BarneaGoraly et al. 2004; Alexander et al. 2007; Keller et al. 2007), body (Barnea-Goraly et al. 2004), posterior midbody (Keller et al. 2007), and splenium (Keller et al. 2007; Alexander et al. 2007). There is also evidence that autism involves elevated MD in the total CC, genu, and callosal body (Alexander et al. 2007). Closer examination across indiivduals with autism suggested the possibility of a autism subphenotype involving low FA and elevated MD throughout the callsoum. Age appears to be atypically correlated with CC structure in autism. Unlike controls, autistic subjects did not exhibit a positive correlation between age and $\mathrm{CC}$ volume, total callosal FA values, and regional callosal FA values. However, these age-related differences did not account for the overall group differences in $\mathrm{CC}$ volume, FA, or MD (Alexander et al. 2007).

Callosal structure correlated with behavioral testing in autistic subjects, but not in controls (Alexander et al. 2007). FA was positively correlated with PIQ and MD was negatively correlated with PIQ for the total CC and each callosal subregion. Additionally, processing speed scores correlated positively with FA in the genu and negatively with MD in the splenium and total CC. However, CC measures did not correlate with scores on autism diagnostic tests in the autism sample.

fMRI evidence has revealed functional underconnectivity between association areas in autism (Just et al. 2007; Mottron et al. 2001; Mottron et al. 2003; Pelphrey et al. 2004), but intact connectivity between sensory areas (Mottron et al. 2003). Intrahemispheric functional connectivity between frontal and parietal areas was reportedly positively correlated with genu area in autism, while these variables were unrelated in controls (Just et al. 2007). Fronto-parietal functional connectivity was also inversely correlated with increases in autism diagnostic scores.

\section{Conclusion}

Both genetic and environmentally caused birth defects often involve callosal malformations, with particular vulnerability in the posterior callosum (Tables 1 and 2). Although 


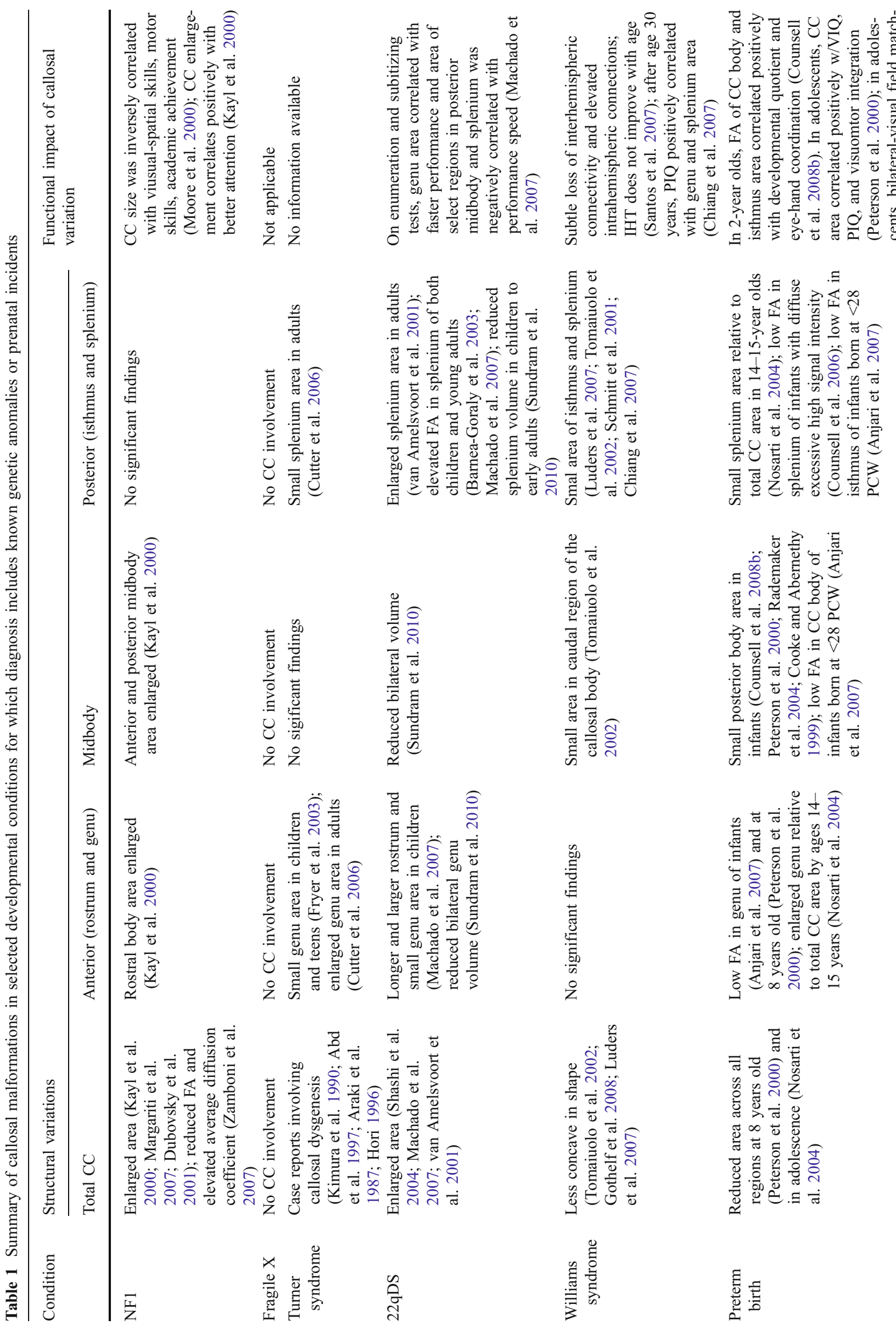


splenial structure correlates with language skills in typical subjects, in developmentally impaired populations both over- and under-development of the splenium results in impairments of visuospatial skills, attention, and motor coordination. This may indicate that effective callosal connections, while helpful for refining language, are uniquely essential for spatial, attentional, and motor skills. In addition to deficits in those areas, individuals with reduced posterior callosal connections also have subtle impairments in IHT, diminished processing speed during complex tasks, and social-skill impairments, a profile similar to that found in AgCC. This suggests that in addition to the general cognitive effects of callosal malformation, callosal reduction has a unique behavioral impact on social skills and other forms of rapid problem solving in developmental disorders. A general observation is that callosal area is positively correlated with attention, regardless of how other comorbid conditions may impact callosal structure. For example, callosal overgrowth in NF1 does not correlate with improved skills in any area other than attention. Also in NF1, as well as in 22qDS, callosal size is relatively reduced in subjects who have comorbid ADHD.

The inventory of callosal contributions to the developmental disorders I have reviewed here also points to the need for future studies and broader review of this topic. Perhaps most simply, the systematic collection of data on callosal volume and FA values should become more commonplace with the widespread availability of highresolution structural and diffusion MRI, and with the easy availability of analysis packages. The accrual of larger sample sizes in relation to the points discussed will help tremendously, not only to establish their reliability, but also to go to the next stage of quantification, which will be to look at variability across subjects. Finally, these methods should be applied to all developmental and behavioral syndromes which involve callosal malformation (including conditions not described here such as retardation syndrome (Gabrielli et al. 2002) and obsessive-compulsive disorder (Rosenberg et al. 1997)). Some such efforts will no doubt contribute to the identification of subtypes of syndromes that are currently diagnosed as a single disorder.

More challenging future directions will be to elucidate the precise functional contributions of the corpus callosum in developmental disorders. Beyond the descriptive and correlational findings, we would like to know how and why callosal malformation contributes to the impairments in behavior, emotion, and cognition seen in the varied disorders. This is a more difficult problem, but there are clear leads to explore, some of which I have suggested in this review. Language function, executive function and social cognition seem to be three domains that deserve special interest, and that are also some of the most prominent contributors to the real-life impairments patients' 
Table 2 Summary of callosal malformations in select developmental disabilities that are diagnosed solely by behavior patterns

\begin{tabular}{|c|c|c|c|c|c|}
\hline \multirow[t]{2}{*}{ Condition } & \multicolumn{4}{|l|}{ Structural variations } & \multirow{2}{*}{$\begin{array}{l}\text { Functional impact } \\
\text { of callosal variation }\end{array}$} \\
\hline & Total CC & $\begin{array}{l}\text { Anterior (rostrum } \\
\text { and genu) }\end{array}$ & Midbody & $\begin{array}{l}\text { Posterior (isthmus } \\
\text { and splenium) }\end{array}$ & \\
\hline $\begin{array}{l}\text { Developmental } \\
\text { language } \\
\text { delay }\end{array}$ & $\begin{array}{l}\text { No significant } \\
\text { findings }\end{array}$ & $\begin{array}{l}\text { Low FA in genu } \\
\text { (Kim et al. 2006) }\end{array}$ & $\begin{array}{l}\text { No significant } \\
\text { findings }\end{array}$ & $\begin{array}{l}\text { Slightly smaller } \\
\text { splenium (Preis et al. } \\
\text { 2000) }\end{array}$ & $\begin{array}{l}\text { Sensory-motor deficits } \\
\text { during IHT task in } \\
\text { children (Fabbro et al. } \\
\text { 2002) }\end{array}$ \\
\hline Dyslexia & $\begin{array}{l}\text { No significant } \\
\text { findings }\end{array}$ & No significant findings & $\begin{array}{l}\text { No significant } \\
\text { findings }\end{array}$ & $\begin{array}{l}\text { Enlarged splenium } \\
\text { (Duara et al. 1991; } \\
\text { Rumsey et al. 1996; } \\
\text { Kilian et al. 2008) }\end{array}$ & $\begin{array}{l}\text { Phonological processing } \\
\text { skill correlates with IHT } \\
\text { of tactile info in dyslexic } \\
\text { adults (Moore et al. } \\
\text { 1996); in families with } \\
\text { reading disorder, total } \\
\text { CC area and area of CC } \\
\text { body correlated } \\
\text { positively with oral } \\
\text { reading skill, even when } \\
\text { controlling for gender } \\
\text { and IQ (Fine et al. 2007); } \\
\text { in hildren with a range of } \\
\text { reading skill, FA of } \\
\text { splenium correlated } \\
\text { negatively correlated } \\
\text { with reading skill } \\
\text { (Dougherty et al. 2007; } \\
\text { Odegard et al. 2009) }\end{array}$ \\
\hline ADHD & $\begin{array}{l}\text { Case reports } \\
\text { involving callosal } \\
\text { dysgenesis and } \\
\text { ADHD (Roessner } \\
\text { et al. 2004); Small } \\
\text { area (Hynd et al. } \\
\text { 1991; Hill et al. } \\
\text { 2003) }\end{array}$ & $\begin{array}{l}\text { Small rostral body in } \\
\text { males (Hutchinson et al. } \\
\text { 2008) }\end{array}$ & $\begin{array}{l}\text { No significant } \\
\text { findings }\end{array}$ & $\begin{array}{l}\text { Smaller splenium in } \\
\text { mixed-gender sample } \\
\text { but no difference from } \\
\text { controls in male-only } \\
\text { studies (Hutchinson et } \\
\text { al. 2008; Valera et al. } \\
\text { 2007); Splenium area } \\
\text { did not differ from con- } \\
\text { trols when comorbid } \\
\text { conditions were exclud- } \\
\text { ed (Hill et al. 2003; } \\
\text { Semrud-Clikeman et al. } \\
\text { 1994; Lyoo et al. 1996) }\end{array}$ & $\begin{array}{l}\text { Reduced left to right } \\
\text { transcallosally mediated } \\
\text { motor inhibition in } \\
\text { children with ADHD } \\
\text { (Buchmann et al. 2003; } \\
\text { Gilbert et al. 2004; Moll } \\
\text { et al. 2000); Slower } \\
\text { right-to-left transfer in } \\
\text { adults with inattentive- } \\
\text { type ADHD and faster } \\
\text { left-to-right transfer in } \\
\text { adults with combined- } \\
\text { type ADHD (Rolfe et al. } \\
\text { 2007); rostrum area was } \\
\text { negatively correlated } \\
\text { with hyperactivity and } \\
\text { impulsivity in males } \\
\text { children with ADHD } \\
\text { (Giedd et al. 1994) }\end{array}$ \\
\hline Autism & $\begin{array}{l}\text { Small area } \\
\text { (Alexander } \\
\text { et al. 2007; Egaas } \\
\text { et al. 1995; Manes } \\
\text { et al. 1999; Boger- } \\
\text { Megiddo et al. } \\
\text { 2006); Low FA } \\
\text { (Alexander et al. } \\
\text { 2007) }\end{array}$ & $\begin{array}{l}\text { Small anterior area } \\
\text { (Manes et al. 1999; } \\
\text { Kilian et al. 2008; } \\
\text { Hardan et al. 2000; } \\
\text { Chung et al. 2004; Vidal } \\
\text { et al. 2006; Just et al. } \\
\text { 2007); Low FA of genu } \\
\text { (Alexander et al. 2007; } \\
\text { Barnea-Goraly et al. } \\
\text { 2004; Keller et al. 2007) }\end{array}$ & $\begin{array}{l}\text { Low FA in } \\
\text { body } \\
\text { (Barnea- } \\
\text { Goraly et al. } \\
\text { 2004) and } \\
\text { posterior } \\
\text { midbody } \\
\text { (Keller et al. } \\
\text { 2007) }\end{array}$ & $\begin{array}{l}\text { Small posterior area } \\
\text { (Piven et al. 1997; } \\
\text { Egaas et al. 1995; Haas } \\
\text { et al. 1996; Waiter et al. } \\
\text { 2005; Just et al. 2007; } \\
\text { Vidal et al. 2006); Low } \\
\text { FA in splenium } \\
\text { (Alexander et al. 2007) }\end{array}$ & $\begin{array}{l}\text { Genu area positively } \\
\text { correlated with fronto- } \\
\text { parietal connectivity } \\
\text { (Just et al. 2007) }\end{array}$ \\
\hline Tourette's & $\begin{array}{l}\text { Small area and low } \\
\text { FA for entire CC } \\
\text { (Plessen et al. 2006) }\end{array}$ & No significant findings & $\begin{array}{l}\text { No significant } \\
\text { findings }\end{array}$ & No significant findings & $\begin{array}{l}\text { Non-significant positive } \\
\text { correlation between tic } \\
\text { severity and both area } \\
\text { and FA of the anterior } \\
\text { callosal sections (Plessen } \\
\text { et al. 2006) }\end{array}$ \\
\hline
\end{tabular}


face. Yet research on this topic will be more of an investment, requiring careful neuropsychological assessment together with functional measures such as EEG, cognitive fMRI studies, or BOLD coherence measures, as well as studies on the genetics involved in callosal development and callosal malformation. Last but not the least, the emphasis on the corpus callosum in this review should not detract from the fact that this is the only one (the largest) of white matter bundles in the human brain. Other large association fiber tracts, as well as microstructural connectivity will all be important additional foci for investigation.

Acknowledgements I am extremely grateful to Ralph Adolphs for helpful comments on this review. Supported in part by grants from National Institutes of Health and the Simons Foundation.

\section{References}

Aalto S, Naatanen P, Wallius E, Metsahonkala L, Stenman H, Niem P, et al. Neuroanatomical substrata of amusement and sadness: a PET activation study using film stimuli. NeuroReport. 2002;13:6773.

Abd SE, Wilson L, Howlin P, Patton MA, Wintgens AM, Wilson R. Agenesis of the corpus callosum in Turner syndrome with ring $\mathrm{X}$. Dev Med Child Neurol. 1997;39:119-24.

Aboitiz F. Brain connections: interhemispheric fiber systems and anatomical brain asymmetries in humans. Biol Res. 1992;25:51-61.

Aboitiz F, Scheibel AB, Fisher RS, Zaidel E. Fiber composition of the human corpus callosum. Brain Res. 1992a;598:143-53.

Aboitiz F, Scheibel AB, Fisher RS, Zaidel E. Individual differences in brain asymmetries and fiber composition in the human corpus callosum. Brain Res. 1992b;598:154-61.

Alexander AL, Lee JE, Lazar M, Boudos R, Dubray MB, Oakes TR, et al. Diffusion tensor imaging of the corpus callosum in Autism. Neuroimage. 2007;34:61-73.

Anderson NG, Laurent I, Cook N, Woodward L. Growth rate of corpus callosum in very premature infants. Am J Neuroradiol. 2005;26(10):2685-90.

Anderson NG, Laurent I, Woodward LJ. Detection of impaired growth of the corpus callosum in premature infants. Pediatrics. 2006;118 (3):951-60.

Anjari M, Srinivasan L, Allsop JM, Hajnal JV, Rutherford MA, Edwards $\mathrm{AD}$, et al. Diffusion tensor imaging with tract-based spatial statistics reveals local white matter abnormalities in preterm infants. Neuroimage. 2007;35:1021-7.

Antshel KM, Conchelos J, Lanzetta G, Fremont W, Kates WR. Behavior and corpus callosum morphology relationships in velocardiofacial syndrome (22q11.2 deletion syndrome). Psychiatry Res. 2005;138:235-45.

Antshel KM, Aneja A, Strunge L, Peebles J, Fremont WP, Stallone K, et al. Autistic spectrum disorders in velo-cardio facial syndrome (22q11.2 deletion). J Autism Dev Disord. 2007;37:1776-86.

Araki K, Matsumoto K, Shiraishi T, Ogura H, Kurashige T, Kitamura I. Turner's syndrome with agenesis of the corpus callosum, Hashimoto's thyroiditis and horseshoe kidney. Acta Paediatr Jpn. 1987;29:622-6.

Arnold PD, Siegel-Bartelt J, Cytrynbaum C, Teshima I, Schachar R. Velo-cardio-facial syndrome: implications of microdeletion 22q11 for schizophrenia and mood disorders. Am J Med Genet. 2001;105:354-62.
Badaruddin DH, Andrews GL, Bölte S, Schilmoeller KJ, Schilmoeller G, Paul LK, et al. Social and behavioral problems of children with agenesis of the corpus callosum. Child Psychiatry Hum Dev. 2007;38:287-302.

Baker LL, Barkovich AJ. The large temporal horn: MR analysis in developmental brain anomalies versus hydrocephalus. AJNR Am J Neuroradiol. 1992;13:115-22.

Banich M, Brown WS. A life-span perspective on interaction between the cerebral hemispheres. Dev Neuropsychol. 2000;18:1-10.

Barkovich AJ, Kjos BO. Normal postnatal development of the corpus callosum as demonstrated by MR imaging. AJNR Am J Neuroradiol. 1988;9:487-91.

Barkovich AJ, Norman D. Anomalies of the corpus callosum: correlation with further anomalies of the brain. AJR Am J Roentgenol. 1988;151:171-9.

Barkovich AJ, Gilles L, Evrard P. Formation, maturation, and disorders of white matter. AJNR Am J Neuroradiol. 1992;13:447-61.

Barnea-Goraly N, Menon V, Krasnow B, Ko A, Reiss A, Eliez S. Investigation of white matter structure in velocardiofacial syndrome: a diffusion tensor imaging study. Am J Psychiatry. 2003;160:1863-9.

Barnea-Goraly N, Kwon H, Menon V, Eliez S, Lotspeich L, Reiss AL. White matter structure in autism: preliminary evidence from diffusion tensor imaging. Biol Psychiatry. 2004;55:323-6.

Basser PJ, Pajevic S, Pierpaoli C, Duda J, Aldroubi A. In vivo fiber tractography using DT-MRI data. Magn Reson Med. 2000;44:625-32.

Baumgardner TL, Reiss AL, Freund LS, Abrams MT. Specification of the neurobehavioral phenotype in males with fragile $\mathrm{X}$ syndrome. Pediatrics. 1995;95:744-52.

Bearden CE, Woodin MF, Wang PP, Moss E, McDonald-McGinn D, Zackai E, et al. The neurocognitive phenotype of the $22 \mathrm{q} 11.2$ deletion syndrome: selective deficit in visual-spatial memory. J Clin Exp Neuropsychol. 2001;23:447-64.

Bearden CE, Van Erp TG, Dutton RA, Lee AD, Simon TJ, Cannon $\mathrm{TD}$, et al. Alterations in midline cortical thickness and gyrification patterns mapped in children with 22q11.2 deletions. Cereb Cortex. 2009; 19:115-26.

Beckel-Mitchener A, Greenough WT. Correlates across the structural, functional, and molecular phenotypes of fragile $\mathrm{X}$ syndrome. Ment Retard Dev Disabil Res Rev. 2004;10:53-9.

Bedeschi MF, Bonaglia MC, Grasso R, Pellegri A, Garghentino RR, Battaglia MA, et al. Agenesis of the corpus callosum: clinical and genetic study in 63 young patients. Pediatr Neurol. 2006;34:186-93.

Behrens TE, Berg HJ, Jbabdi S, Rushworth MF, Woolrich MW. Probabilistic diffusion tractography with multiple fibre orientations: what can we gain? Neuroimage. 2007;34:144-55.

Bishop DV. The underlying nature of specific language impairment. J Child Psychol Psychiatry. 1992;33:3-66.

Bishop DV. Is specific language impairment a valid diagnostic category? Genetic and psycholinguistic evidence. Philos Trans R Soc Lond B Biol Sci. 1994;346:105-11.

Bishop DVM, Adams C. A prospective study of the relationship between specific language impairment, phonological disorders, and reading retardation. J Child Psychol Psychiatry. 1990;31:1027-50

Bloom JS, Hynd GW. The role of the corpus callosum in interhemispheric transfer of information: excitation or inhibition? Neuropsychol Rev. 2005;15:59-71.

Boardman JP, Counsell SJ, Rueckert D, Kapellou O, Bhatia KK, Aljabar P, et al. Abnormal deep grey matter development following preterm birth detected using deformation-based morphometry. Neuroimage. 2006;32:70-8. 
Bodensteiner J, Schaefer GB, Breeding L, Cowan L. Hypoplasia of the corpus callosum: a study of 445 consecutive MRI scans. J Child Neurol. 1994;9:47-9.

Bogen J. Split-brain syndromes. In: Frederiks J, editor. Handbook of clinical neurology. Amsterdam: Elsevier; 1985.

Bogen J. The Callosal Syndrome. In: Heilman K, Valenstein E, editors. Clinical neuropsychology. New York: Oxford University Press; 1979.

Bogen J, Bogen GM. Creativity and the corpus callosum. Psychiatr Clin North Am. 1998;11:293-301.

Boger-Megiddo I, Shaw DW, Friedman SD, Sparks BF, Artru AA, Giedd $\mathrm{JN}$, et al. Corpus callosum morphometrics in young children with autism spectrum disorder. J Autism Dev Disord. 2006;36:733-9.

Borod JC, Bloom RL, Brickman AM, Nakhutina L, Curko EA. Emotional processing deficitis in individuals with unilateral brain damage. Appl Neuropsychol. 2002;9:23-36.

Brewer VR, Moore BD, Hiscock M. Learning disability subtypes in children with neurofibromatosis. J Learn Disabil. 1997;30:52133.

Brown W, Paul L. Cognitive and psychosocial deficits in agenesis of the corpus callosum with normal intelligence. Cogn Neuropsychiatry. 2000;5:135-57.

Brown LN, Sainsbury RS. Hemispheric equivalence and age-related differences in judgments of simultaneity to somatosensory stimuli. J Clin Exp Neuropsychol. 2000;22:587-98.

Brown WS, Jeeves MA, Dietrich R, Burnison DS. Bilateral field advantage and evoked potential interhemispheric transmission in commissurotomy and callosal agenesis. Neuropsychologia. 1999;37:1165-80.

Brown WS, Thrasher ED, Paul LK. Interhemispheric Stroop effects in partial and complete agenesis of the corpus callosum. J Int Neuropsychol Soc. 2001;7:302-11.

Brown WS, Paul LK, Symington M, Dietrich R. Comprehension of humor in primary agenesis of the corpus callosum. Neuropsychologia. 2005a;43:906-16.

Brown WS, Symingtion M, Vanlancker-Sidtis D, Dietrich R, Paul LK. Paralinguistic processing in children with callosal agenesis: emergence of neurolinguistic deficits. Brain Lang. 2005b;93:135-9.

Buchanan DC, Waterhouse GJ, West Jr SC. A proposed neurophysiological basis of alexithymia. Psychother Psychosom. 1980;34:248 55 .

Buchmann J, Wolters A, Haessler F, Bohne S, Nordbeck R, Kunesch E. Disturbed transcallosally mediated motor inhibition in children with attention deficit hyperactivity disorder (ADHD). Clin Neurophysiol. 2003;114:2036-42.

Buchmann J, Gierow W, Weber S, Hoeppner J, Klauer T, Wittstock M, et al. Modulation of transcallosally mediated motor inhibition in children with attention deficit hyperactivity disorder (ADHD) by medication with methylphenidate (MPH). Neurosci Lett. 2006;405:14-8.

Byrd SE, Harwood-Nash DC, Fitz CR. Absence of the corpus callosum: computed tomographic evaluation in infants and children. J Can Assoc Radiol. 1978;29:108-12.

Carpenter MB, Sutin J. Human neuroanatomy. Baltimore: Williams \& Wilkins; 1983.

Cascio C, Styner M, Smith RG, Poe MD. Reduced relationship to cortical white matter volume revealed by tractography-based segmentation of the corpus callosum in young children with developmental delay. Am J Psychiatry. 2006;163:2157-63.

Castellanos FX, Giedd JN, Eckburg P, Marsh WL, Vaituzis AC, Kaysen D, et al. Quantitative morphology of the caudate nucleus in attention deficit hyperactivity disorder. Am J Psychiatry. 1994;151:1791-6.

Chiang MC, Reiss AL, Lee AD, Bellugi U, Galaburda AM, Korenberg JR, et al. 3D pattern of brain abnormalities in Williams syndrome visualized using tensor-based morphometry. Neuroimage. 2007;36:1096-109.

Chiarello C. A house divided? Cognitive functioning with callosal agenesis. Brain Lang. 1980;11:128-58.
Chung MK, Dalton KM, Alexander AL, Davidson RJ. Less white matter concentration in autism: 2D voxel-based morphometry. Neuroimage. 2004;23:242-51.

Clahsen $\mathrm{H}$. The grammatical characterization of developmental dysphasia. Linguistics. 1989;27:897-920.

Clark C, Klonoff H, Hayden M. Regional cerebral glucose metabolism in Turner syndrome. Can J Neurol Sci. 1990;17:140-4.

Clarke JM, Zaidel E. Simple reaction times to lateralized light flashes. Varieties of interhemispheric communication routes. Brain. 1989;112:849-70.

Collaer ML, Geffner ME, Kaufman FR, Buckingham B, Hines M. Cognitive and behavioral characteristics of turner syndrome: exploring a role for ovarian hormones in female sexual differentiation. Horm Behav. 2002;41:139-55.

Conners F, Olson R. Reading comprehension in dyslexic and normal readers: a component skills analysis. In: Balota DA, Flores D'Arcais GB, Rayner K, editors. Comprehension processes in reading. Hillsdale: Lawrence Earlbaum; 1990.

Cooke RW, Abernethy LJ. Cranial magnetic resonance imaging and school performance in very low birth weight infants in adolescence. Arch Dis Child Fetal Neonatal Ed. 1999;81:F116-21.

Counsell SJ, Shen Y, Boardman JP, Larkman DJ, Kapellou O, Ward P, et al. Axial and radial diffusivity in preterm infants who have diffuse white matter changes on magnetic resonance imaging at term-equivalent age. Pediatrics. 2006;117:376-86.

Counsell SJ, Edwards AD, Chew A, Anjari M. Specific relations between neurodevelopmental abilities and white matter microstructure in children born preterm. Brain. 2008a;131(Pt 12):3201-8.

Counsell SJ, Edwards AD, Chew A, Anjari M, Dyet LE, Srinivasan L, et al. Specific relations between neurodevelopmental abilities and white matter microstructure in children born preterm. Brain. 2008b;131:3201-8.

Cutter WJ, Daly EM, Robertson DM, Chitnis XA, Van Amelsvoort $\mathrm{TA}$, Simmons $\mathrm{A}$, et al. Influence of $\mathrm{X}$ chromosome and hormones on human brain development: a magnetic resonance imaging and proton magnetic resonance spectroscopy study of Turner syndrome. Biol Psychiatry. 2006;59:273-83.

Cutting LE, Koth CW, Burnette CP, Abrams MT, Kaufmann WE, Denckla MB. Relationship of cognitive functioning, whole brain volumes, and T2-weighted hyperintensities in neurofibromatosis1. J Child Neurol. 2000a; 15:157-60.

Cutting LE, Koth CW, Denckla MB. How children with neurofibromatosis type 1 differ from "typical" learning disabled clinic attenders: nonverbal learning disabilities revisited. Dev Neuropsychol. 2000b;17:29-47.

Cutting LE, Cooper KL, Koth CW, Mostofsky SH, Kates WR, Denckla MB, et al. Megalencephaly in NF1: predominantly white matter contribution and mitigation by ADHD. Neurology. 2002;59:1388-94.

David AS, Wacharasindhu A, Lishman WA. Severe psychiatric disturbance and abnormalities of the corpus callosum: review and case series. J Neurol Neurosurg Psychiatry. 1993;56:85-93.

De Lacoste MC, Kirkpatrick JB, Ross ED. Topography of the human corpus callosum. J Neuropathol Exp Neurol. 1985;44:578-91.

Dorion AA, Chantome M, Hasbound D, Zouaoui A, Marsault C, Capron C, et al. Hemispheric asymmetry and corpus callosum morphometry: a magnetic resonance imaging study. Neurosci Res. 2000;36:9-13.

Dorn MB, Mazzocco MM, Hagerman RJ. Behavioral and psychiatric disorders in adult male carriers of fragile X. J Am Acad Child Adolesc Psychiatry. 1994;33:256-64.

Dougherty R, Ben-Shachar M, Bammer R, Brewer A, Wandell B. Functional organization of human occipital-callosal fiber tracts. PNAS. 2005;102:7350-5.

Dougherty R, Ben-Shachar M, Deutsch GK. Temporal-callosal pathway diffusivity predicts phonological skills in children. In: Proceedings of the National Academy of Sciences, 2007. 
Downey J, Ehrhardt AA, Gruen R, Bell JJ, Morishima A. Psychopathology and social functioning in women with Turner syndrome. J Nerv Ment Dis. 1989;177:191-201.

Duara R, Kushch A, Gross-Glenn K, Barker WW, Jallad B, Pascal S, et al. Neuroanatomic differences between dyslexic and normal readers on magnetic resonance imaging scans. Arch Neurol. 1991;48:410-6.

Dubovsky EC, Booth TN, Vezina G, Samango-Sprouse CA, Palmer $\mathrm{KM}$, Brasseux CO. MR imaging of the corpus callosum in pediatric patients with neurofibromatosis type 1. AJNR Am J Neuroradiol. 2001;22:190-5.

Durston S. A review of the biological bases of ADHD: what have we learned from imaging studies? Ment Retard Dev Disabil Res Rev. 2003;9:184-95.

Dyet LE, Kennea N, Counsell SJ, Maalouf EF, Ajayi-Obe M, Duggan $\mathrm{PJ}$, et al. Natural history of brain lesions in extremely preterm infants studied with serial magnetic resonance imaging from birth and neurodevelopmental assessment. Pediatrics. 2006;118:53648.

Eckstein K, Friederici AD. Late interaction of syntactic and prosodic processes in sentence comprehension as revealed by ERPs. Cogn Brain Res. 2005;25:130-43.

Eckstein K, Friederici AD. It's early: event-related potential evidence for initial interaction of syntax and prosody in speech comprehension. J Cogn Neurosci. 2006;18:1696-711.

Egaas B, Courchesne E, Saitoh O. Reduced size of corpus callosum in autism. Arch Neurol. 1995;52:794-801.

Eliez S, Schmitt JE, White CD, Reiss AL. Children and adolescents with velocardiofacial syndrome: a volumetric MRI study. Am J Psychiatry. 2000;157:409-15.

Eliez S, Blasey CM, Freund LS, Hastie T, Reiss AL. Brain anatomy, gender and IQ in children and adolescents with fragile $\mathrm{X}$ syndrome. Brain. 2001;124:1610-8.

Fabbro F, Pesenti S, Facoetti A, Bonanomi M, Libera L, Lorusso ML. Callosal transfer in different subtypes of developmental dyslexia. Cortex; a journal devoted to the study of the nervous system and behavior. 2001;37:65-73.

Fabbro F, Libera L, Tavano A. A callosal transfer deficit in children with developmental language disorder. Neuropsychologia. 2002;40:1541-6.

Fine SE, Weissman A, Gerdes M, Pinto-Martin J, Zackai EH, McDonald-McGinn DM, et al. Autism spectrum disorders and symptoms in children with molecularly confirmed 22q11.2 deletion syndrome. J Autism Dev Disord. 2005;35:461-70.

Fine J, Semrud-Clikeman M, Keith T, Stapleton L, Hynd GW. Reading and the corpus callosum: an MRI family study of volume and area. Neuropsychology. 2007;21:235-41.

Fischer M, Ryan SB, Dobyns WB. Mechanisms of interhemispheric transfer and patterns of cognitive function in acallosal patients of normal intelligence. Arch Neurol. 1992;49:271-7.

Franz EA, Fahey S. Developmental change in interhemispheric communication: evidence from bimanual cost. Psychol Sci. 2007;18:1030-1.

Freund LS, Reiss AL, Hagerman R, Vinogradov S. Chromosome fragility and psychopathology in obligate female carriers of the fragile X chromosome. Arch Gen Psychiatry. 1992;49:54-60.

Friederici AD. The neural basis of language development and its impairment. Neuron. 2006;52:941-52.

Friederici AD, Alter K. Lateralization of auditory language functions: a dynamic dual pathway model. Brain Lang. 2004;89:267-76.

Friedman JM, Birch PH. Type 1 neurofibromatosis: a descriptive analysis of the disorder in 1, 728 patients. Am J Med Genet. 1997;70:138-43.

Fryer SL, Kwon H, Eliez S, Reiss AL. Corpus callosum and posterior fossa development in monozygotic females: a morphometric MRI study of Turner syndrome. Dev Med Child Neurol. 2003;45:320-4.
Fryer SL, Frank LR, Spadoni AD. Microstructural integrity of the corpus callosum linked with neuropsychological performance in Adolescents. Brain Cogn. 2008;67(2):225-33.

Gabrielli O, Bruni S, Coppa GV, Carloni I, Polonara G, Regnicolo L, et al. White-matter alterations and callosal abnormalities in syndromic patients with mental retardation. J Child Neurol. 2002;17:164-8.

Galaburda AM, Holinger DP, Bellugi U, Sherman GF. Williams syndrome: neuronal size and neuronal-packing density in primary visual cortex. Arch Neurol. 2002;59:1461-7.

Galvez R, Greenough WT. Sequence of abnormal dendritic spine development in primary somatosensory cortex of a mouse model of the fragile X mental retardation syndrome. Am J Med Genet A. $2005 ; 135: 155-60$

Gaser C, Luders E, Thompson PM, Lee AD, Dutton RA, Geaga JA, et al. Increased local gyrification mapped in Williams syndrome. Neuroimage. 2006;33:46-54.

Giedd JN, Castellanos FX, Casey BJ, Kozuch P, King AC, Hamburger $\mathrm{SD}$, et al. Quantitative morphology of the corpus callosum in attention deficit hyperactivity disorder. Am J Psychiatry. 1994:151:665-9.

Giedd J, Blumenthal J, Jeffries N, Rajapakse JC, Vaituzis AC, Liu H, et al. Development of the human corpus callosum during childhood and adolescence: a longitudinal MRI study. Prog Neuropsychopharmacol Biol Psychiatry. 1999;23:571-88.

Gilbert DL, Bansal AS, Sethuraman G, Sallee FR, Zhang J, Lipps T, et al. Association of cortical disinhibition with tic, ADHD, and OCD severity in Tourette syndrome. Mov Disord. 2004;19:416-25.

Glass H, Shaw G, Ma C, Sherr EH. Agenesis of the corpus callosum in California 1983-2003: a population-based study. Am J Med Genet A. 2008;146A:2495-500.

Goodyear PW, Bannister CM, Russell S, Rimmer S. Outcome in prenatally diagnosed fetal agenesis of the corpus callosum. Fetal Diagn Ther. 2001;16:139-45.

Gordon HW, Sperry RW. Lateralization of olfactory perception in the surgically separated hemispheres in man. Neuropsychologia. 1969;7:111-20.

Gothelf D, Presburger G, Zohar AH, Burg M, Nahmani A, Frydman $\mathrm{M}$, et al. Obsessive-compulsive disorder in patients with velocardiofacial (22q11 deletion) syndrome. Am J Med Genet B Neuropsychiatr Genet. 2004;126B:99-105.

Gothelf D, Michaelovsky E, Frisch A, Zohar AH, Presburger G, Burg $\mathrm{M}$, et al. Association of the low-activity COMT $158 \mathrm{Met}$ allele with ADHD and OCD in subjects with velocardiofacial syndrome. Int J Neuropsychopharmacol. 2007;10:301-8.

Gothelf D, Searcy YM, Reilly J, Lai PT, Lanre-Amos T, Mills D, et al. Association between cerebral shape and social use of language in Williams syndrome. Am J Med Genet A. 2008;146A:2753-61.

Greenwood RS, Tupler LA, Whitt JK, Buu A, Dombeck CB, Harp AG, et al. Brain morphometry, T2-weighted hyperintensities, and IQ in children with neurofibromatosis type 1. Arch Neurol. 2005;62:1904-8.

Haas RH, Townsend J, Courchesne E, Lincoln AJ, Schreibman L, Yeung-Courchesne R. Neurologic abnormalities in infantile autism. J Child Neurol. 1996;11:84-92.

Hagelthorn KM, BRown WS, Amano S, Asarnow R. Normal development of bilateral field advantage and evoked potential interhemispheric transmission time. Dev Neuropsychol. 2000;18:11-31.

Hamilton WJ, Boyd JD, Maossman HW. Human embryology. Baltimore: Williams \& Wilkins; 1962.

Hardan A, Minshew N, Keshavan MS. Corpus callosum size in autism. Neurology. 2000;55:1033-6.

Herbert MR, Ziegler DA, Makris N, Filipek PA, Kemper TL, Normandin JJ, et al. Localization of white matter volume increase in autism and developmental language disorder. Ann Neurol. 2004;55:530-40. 
Herbert MR, Ziegler DA, Deutsch CK, O'Brien LM, Kennedy DN, Filipek PA, et al. Brain asymmetries in autism and developmental language disorder: a nested whole-brain analysis. Brain. 2005;128:213-26.

Hessl D, Rivera S, Koldewyn K, Cordeiro L, Adams J, Tassone F, et al. Amygdala dysfunction in men with the fragile $\mathrm{X}$ premutation. Brain. 2007;130:404-16.

Hetts SW, Sherr EH, Chao S, Gobuty S, Barkovich AJ. Anomalies of the corpus callosum: an MR analysis of the phenotypic spectrum of associated malformations. AJR Am J Roentgenol. 2006;187:1343-8.

Hill DE, Yeo RA, Campbell RA, Hart B, Vigil J, Brookes W. Magnetic resonance imaging correlates of attention deficit/ hyperactivity disorder in children. Neuropsychology. 2003;17:496-506.

Hodapp RM, Dykens EM, Hagerman RJ, Schreiner R, Lachiewicz AM, Leckman JF. Developmental implications of changing trajectories of IQ in males with fragile X syndrome. J Am Acad Child Adolesc Psychiatry. 1990;29:214-9.

Hoeft F, Barnea-Goraly N, Haas BW, Golarai G, Ng D, Mills D, et al. More is not always better: increased fractional anisotropy of superior longitudinal fasciculus associated with poor visuospatial abilities in Williams syndrome. J Neurosci. 2007;27:11960-5.

Hofer S, Frahm J. Topography of the human corpus callosum revisited-comprehensive fiber tractography using diffusion tensor magnetic resonance imaging. Neuroimage. 2006;32: 989-94.

Hofer S, Merboldt K, Tammer R, Frahm J. Rhesus monkey and human share a similar topography of the corpus callosum as revealed by diffusion tensor MRI in vivo. Cerebral Cortex. 2007;18(5):1079-84.

Hoppe K, Bogen J. Alexithymia in twelve commissurotomized patients. Psychother Psychosom. 1977;28:148-155.

Hori A. Precocious cerebral development associated with agenesis of the corpus callosum in mid-fetal life: a transient syndrome? Acta Neuropathol. 1996;91:120-5.

Hoy EA, Sykes DH, Bill JM, Halliday HL, McClure BG, Reid MM. The social competence of very-low-birthweight children: teacher, peer, and self-perceptions. J Abnorm Child Psychol. 1992;20:123-50.

Huang H, Zhang J, Jiang H, Wakana S, Poetscher L, Miller MI, et al. DTI tractography based parcellation of white matter: application to the mid-sagittal morphology of corpus callosum. Neuroimage. 2005;26:195-205

Huang H, Zhang J, Wakana S, Zhang W, Ren T, Richards LJ, et al. White and gray matter development in human fetal, newborn and pediatric brains. Neuroimage. 2006;33:27-38.

Huang H, Xue R, Zhang J, Ren T, Richards LJ, Yarowsky P, et al. Anatomical characterization of human fetal brain development with diffusion tensor magnetic resonance imaging. J Neurosci. 2009;29:4263-73.

Huber-Okrainec J, Blaser SE, Dennis M. Idiom comprehension deficits in relation to corpus callosum agenesis and hypoplasia in children with spina bifida meningomyelocele. Brain Lang. 2005;93:349-68.

Huppi PS, Maier SE, Peled S, Zientara GP, Barnes P, Jolesz FA, et al. Microstructural development of human newborn cerebral white matter assessed in vivo by diffusion tensor magnetic resonance imaging. Pediatr Res. 1998;44:584-90.

Hutchinson A, Mathias J, Banich M. Corpus callosum morphology in children and adolescents with attention deficit hyperactivity disorder: a meta-analytic review. Neuropsychology. 2008;22:341-9.

Hynd GW, Semrud-Clikeman M, Lorys AR, Novey ES, Eliopulos D. Brain morphology in developmental dyslexia and attention deficit disorder/hyperactivity. Arch Neurol. 1990;47:919-26.
Hynd GW, Semrud-Clikeman M, Lorys AR, Novey ES, Eliopulos D, Lyytinen H. Corpus callosum morphology in attention deficithyperactivity disorder: Morphometric analysis of MRI. J Learn Disabil. 1991;24:141-6.

Hynd GW, Hall J, Novey ES, Eliopulos D, Black K, Gonzalez JJ, et al. Dyslexia and corpus callosum morphology. Arch Neurol. 1995;52:32-8.

Imamura T, Yamadori A, Shiga Y, Sahara M, Abiko H. Is distrurbed transfer of learning in callosal agenesis due to a disconnection syndrome? Behav Neurol. 1994;7:43-8.

Innocenti GM, Price DJ. Exuberance in the development of cortical networks. Nat Rev Neurosci. 2005;6:955-65.

Irwin SA, Galvez R, Greenough WT. Dendritic spine structural anomalies in fragile- $\mathrm{X}$ mental retardation syndrome. Cereb Cortex. 2000;10:1038-44.

Jarvinen-Pasley A, Pollak SD, Yam A, Hill KJ, Grichanik M, Mills D, et al. Atypical hemispheric asymmetry in the perception of negative human vocalizations in individuals with Williams syndrome. Neuropsychologia. 2010;48:1047-52.

Jeeves MA, Silver PH. Interhemispheric transfer of spatial tactile information in callosal agenesis and partial commissurotomy. Cortex. 1988;24:601-4.

Jeeves MA, Russell I, Hof MV, Berlucchi G. Some limits to interhemispheric integration in cases of callosal agenesis and partial commissurotomy. In: Structure and function of the cerebral commissures. London: MacMillan Press; 1979.

Jeret JS, Serur D, Wisniewski K, Fisch C. Frequency of agenesis of the corpus callosum in the developmentally disabled population as determined by computerized tomography. Pediatr Neurosci. 1985;12:101-3.

Jernigan TL, Bellugi U, Sowell ER, Doherty S, Hesselink JR. Cerebral morphologic distinctions between Williams and Down syndromes. Arch Neurol. 1993;50:186-91.

Johansen-Berg H, Della-Maggiore V, Behrens TE, Smith SM, Paus T. Integrity of white matter in the corpus callosum correlates with bimanual co-ordination skills. Neuroimage. 2007;36 Suppl 2:T16-21.

Jones KL, Smith DW. Recognition of the fetal alcohol syndrome in early infancy. Lancet. 1973;302:999-1001.

Josse G, Tzourio-Mazoyer N. Hemispheric specialization for language. Brain Res Review. 2004;44:1-12.

Jovanov-Milosevic N, Culjat M, Kostovic I. Growth of the human corpus callosum: modular and laminar morphogenetic zones. Front Neuroanat. 2009;3:6.

Just MA, Cherkassky VL, Keller TA, Kana RK, Minshew NJ. Functional and anatomical cortical underconnectivity in autism: evidence from an FMRI study of an executive function task and corpus callosum morphometry. Cereb Cortex. 2007;17:951-61.

Kail R. A method for studying the generalized slowing hypothesis in children with specific language impairment. J Speech Hear Res. 1994;37:418-21.

Kates WR, Burnette CP, Jabs EW, Rutberg J, Murphy AM, Grados M, et al. Regional cortical white matter reductions in velocardiofacial syndrome: a volumetric MRI analysis. Biol Psychiatry. 2001;49:677-84.

Kates WR, Antshel KM, Fremont WP, Shprintzen RJ, Strunge LA, Burnette $\mathrm{CP}$, et al. Comparing phenotypes in patients with idiopathic autism to patients with velocardiofacial syndrome (22q11 DS) with and without autism. Am J Med Genet A. 2007;143A:2642-50.

Kayl AE, Moore BD, Slopis JM, Jackson EF, Leeds NE. Quantitative morphology of the corpus callosum in children with neurofibromatosis and attention-deficit hyperactivity disorder. J Child Neurol. 2000;15:90-6.

Keller TA, Kana RK, Just MA. A developmental study of the structural integrity of white matter in autism. NeuroReport. 2007;18:23-7. 
Kier EL, Truwit CL. The normal and abnormal genu of the corpus callosum: an evolutionary, embryologic, anatomic, and MR analysis. AJNR Am J Neuroradiol. 1996;17:1631-41.

Kilian SC, Brown W, Hallam B, McMahon W, Lu J, Johnson M, et al. Regional Callosal Morphology in Autism and Macrocephaly. Dev Neuropsychol. 2008;33:74-99.

Killing J, Insel T. Differential expansion of neural projection systems in primate brain evolution. Neuroreport. 1999;10:14531459.

Kim J, Kim YW, Park CI, Park ES, Kim HH, Lee SK, et al. Diffusiontensor magnetic resonance imaging in children with language impairment. NeuroReport. 2006;17:1279-82.

Kimura M, Nakajima M, Yoshino K. Ullrich-Turner syndrome with agenesis of the corpus callosum. Am J Med Genet. 1990;37:227-8.

Kodituwakku PW. Defining the behavioral phenotype in children with fetal alcohol spectrum disorders: a review. Neurosci Biobehav Rev. 2007;31:192-201.

Kushch A, Gross-Glenn K, Jallad B, Lubs H, Rabin M, Feldman E, et al. Temporal lobe surface area measurements on MRI in normal and dyslexic readers. Neuropsychologia. 1993;31:811-21.

Langleben DD, Austin G, Krikorian G, Ridlehuber HW, Goris ML, Strauss HW. Interhemispheric asymmetry of regional cerebral blood flow in prepubescent boys with attention deficit hyperactivity disorder. Nucl Med Commun. 2001;22:1333-40.

Larsen JP, Hoien T, Lundberg I, Odegaard H. MRI evaluation of the size and symmetry of the planum temporale in adolescents with developmental dyslexia. Brain Lang. 1990;39:289-301.

Lassonde M, Sauerwein H, Chicoine AJ, Geoffroy G. Absence of disconnexion syndrome in callosal agenesis and early callosotomy: brain reorganization or lack of structural specificity during ontogeny? Neuropsychologia. 1991;29:481-95.

Lawrence K, Campbell R, Swettenham J, Terstegge J, Akers R, Coleman $\mathrm{M}$, et al. Interpreting gaze in Turner syndrome: impaired sensitivity to intention and emotion, but preservation of social cueing. Neuropsychologia. 2003a;41:894-905.

Lawrence K, Kuntsi J, Coleman M, Campbell R, Skuse D. Face and emotion recognition deficits in Turner syndrome: a possible role for X-linked genes in amygdala development. Neuropsychology. 2003b;17:39-49.

Lebel C, Walker L, Leemans A, Phillips LJ, Beaulieu C. Microstructural maturation of the human brain from childhood to adulthood. Neuroimage. 2008;40:1044-55.

Lee AD, Leow AD, Lu A, Reiss AL, Hall S, Chiang MC, et al. 3D pattern of brain abnormalities in Fragile $\mathrm{X}$ syndrome visualized using tensor-based morphometry. Neuroimage. 2007;34:92438.

Lemoine P, Harousseau H, Baorteryu J-P, Menuet J-C. Les enfants des parents alcooliques: anomalies observées. A proposos de 1127 cas [Children of alcoholic parents: Abnormalities observed in 127 cases]. Ouest Med. 1968;21:476-82.

Leonard C, Eckert M, Given B, Virginia B, Eden G. Individual differences in anatomy predict reading and oral language impairments in children. Brain. 2006;129:3329-42.

Levy F, Farrow M. Working memory in ADHD: prefrontal/parietal connections. Curr Drug Targets. 2001;2:347-52.

Liederman J, Merola J, Martinez S. Interhemispheric collaboration in response to simultaneous bilateral input. Neuropsychologia. 1985;23:673-83.

Livingstone MS, Rosen GD, Drislane FW, Galaburda AM. Physiological and anatomical evidence for a magnocellular defect in developmental dyslexia. Proc Natl Acad Sci USA. 1991;88:7943-7.

Luders E, Di Paola M, Tomaiuolo F, Thompson PM, Toga AW, Vicari S, et al. Callosal morphology in Williams syndrome: a new evaluation of shape and thickness. NeuroReport. 2007;18:203-7.
Lyoo IK, Noam GG, Lee CK, Lee HK, Kennedy BP, Renshaw PF. The corpus callosum and lateral ventricles in children with attention-deficit hyperactivity disorder: A brain magnetic resonance imaging study. Biol Psychiatry. 1996;40:1060-3.

Maalouf EF, Duggan PJ, Rutherford MA, Counsell SJ, Fletcher AM, Battin M, et al. Magnetic resonance imaging of the brain in a cohort of extremely preterm infants. J Pediatr. 1999;135:351-7.

Machado AM, Simon TJ, Nguyen V, McDonald-McGinn DM, Zackai $\mathrm{EH}$, Gee JC. Corpus callosum morphology and ventricular size in chromosome 22q11.2 deletion syndrome. Brain Res. 2007;1131:197-210.

Manes F, Piven J, Vrancic D, Nanclares V, Plebst C, Starkstein SE. An MRI study of the corpus callosum and cerebellum in mentally retarded autistic individuals. J Neuropsychiatry Clin Neurosci. 1999;11:470-4.

Marenco S, Siuta MA, Kippenhan JS, Grodofsky S, Chang WL, Kohn $\mathrm{P}$, et al. Genetic contributions to white matter architecture revealed by diffusion tensor imaging in Williams syndrome. Proc Natl Acad Sci USA. 2007;104:15117-22.

Margariti PN, Blekas K, Katzioti FG, Zikou AK, Tzoufi M, Argyropoulou MI. Magnetization transfer ratio and volumetric analysis of the brain in macrocephalic patients with neurofibromatosis type 1. Eur Radiol. 2007;17:433-8.

Martens MA, Wilson SJ, Reutens DC. Research Review: Williams syndrome: a critical review of the cognitive, behavioral, and neuroanatomical phenotype. J Child Psychol Psychiatry. 2008;49:576-608.

Mattson SN, Riley EP. A review of the neurobehavioral deficits in children with fetal alcohol syndrome or prenatal exposure to alcohol. Alcohol Clin Exp Res. 1998;22:279-94.

Mattson SN, Riley EP, Gramling L, Delis DC, Jones KL. Neuropsychological comparison of alcohol-exposed children with or without physical features of fetal alcohol syndrome. Neuropsychology. 1998;12:146-53.

Mazzocco MM, Kates WR, Baumgardner TL, Freund LS, Reiss AL. Autistic behaviors among girls with fragile $\mathrm{X}$ syndrome. J Autism Dev Disord. 1997;27:415-35.

McCauley E, Kay T, Ito J, Treder R. The Turner syndrome: cognitive deficits, affective discrimination, and behavior problems. Child Dev. 1987;58:464-73.

McCauley E, Ross JL, Kushner H, Cutler Jr G. Self-esteem and behavior in girls with Turner syndrome. J Dev Behav Pediatr. 1995;16:82-8.

McDonald-McGinn DM, Larossa D, Goldmuntz E, Sullivan K, Eicher $\mathrm{P}$, Gerdes M, et al. The 22q11.2 deletion: screening, diagnostic workup, and outcome of results; report on 181 patients. Genet Test. 1997;1:99-108.

McDonald-McGinn DM, Kirschner R, Goldmuntz E, Sullivan K, Eicher P, Gerdes M, et al. The Philadelphia story: the 22q11.2 deletion: report on 250 patients. Genet Couns. 1999;10:11-24.

Meerwaldt JD. Disturbances of spatial perception in a patient with agenesis of the corpus callosum. Neuropsychologia. 1983;21:161-5.

Merzenich MM, Schreiner C, Jenkins W, Wang X. Neural mechanisms underlying temporal integration, segmentation, and input sequence representation: some implications for the origin of learning disabilities. Ann NY Acad Sci. 1993;682:1-22.

Mesulam MM. From sensation to cognition. Brain. 1998;121(Pt 6): $1013-52$.

Mihrshahi R. The corpus callosum as an evolutionary innovation. J Exp Zool B Mol Dev Evol. 2006;306:8-17.

Miller SP, Vigneron DB, Henry RG, Bohland MA, Ceppi-Cozzio C, Hoffman C, et al. Serial quantitative diffusion tensor MRI of the premature brain: development in newborns with and without injury. Journal of magnetic resonance imaging: JMRI. 2002;16:621-32.

Milner B, Taylor L, Sperry RW. Lateralized suppression of dichotically presented digits after commissural section in man. Science. 1968;161:184-6. 
Moll GH, Heinrich H, Trott G, Wirth S, Rothenberger A. Deficient intracortical inhibition in drug-naive children with attentiondeficit hyperactivity disorder is enhanced by methylphenidate. Neurosci Lett. 2000;284:121-5.

Moore BD, Slopis JM, Jackson EF, De Winter AE, Leeds NE. Brain volume in children with neurofibromatosis type 1: relation to neuropsychological status. Neurology. 2000;54:914-20.

Moore CJ, Daly EM, Schmitz N, Tassone F, Tysoe C, Hagerman RJ, et al. A neuropsychological investigation of male premutation carriers of fragile $X$ syndrome. Neuropsychologia. 2004;42:1934-47.

Moore LH, Brown WS, Markee TE, Theberge DC, Zvi JC. Bimanual coordination in dyslexic adults. Neuropsychologia. 1995;33:781-93.

Moore LH, Brown WS, Markee TE, Theberge DC, Zvi JC. Callosal transfer of finger localization information in phonologically dyslexic adults. Cortex. 1996;32:311-22.

Mori K. Giant interhemispheric cysts associated with agenesis of the corpus callosum. J Neurosurg. 1992;76:224-30.

Morriss MC, Zimmerman RA, Bilaniuk LT. Changes in brain water diffusion during childhood. Neuroradiology. 1999;41(12):92934.

Moses P, Courchesne E, Stiles J, Trauner D, Egaas B, Edwards E. Regional size reduction in the human corpus callosum following pre- and perinatal brain injury. Cereb Cortex. 2000;10:1200-10.

Moss EM, Batshaw ML, Solot CB, Gerdes M, McDonald-McGinn DM, Driscoll DA, et al. Psychoeducational profile of the 22q11.2 microdeletion: A complex pattern. J Pediatr. 1999;134:193-8.

Mostofsky SH, Cooper KL, Kates WR, Denckla MB, Kaufmann WE. Smaller prefrontal and premotor volumes in boys with attentiondeficit/hyperactivity disorder. Biol Psychiatry. 2002;52:785-94.

Mottron L, Morasse K, Belleville S. A study of memory functioning in individuals with autism. J Child Psychol Psychiatry. 2001;42:253-60.

Mottron L, Burack JA, Iarocci G, Belleville S, Enns JT. Locally oriented perception with intact global processing among adolescents with high-functioning autism: evidence from multiple paradigms. J Child Psychol Psychiatry. 2003;44:904-13.

Murphy KC. Schizophrenia and velo-cardio-facial syndrome. Lancet. 2002;359:426-30.

Murphy DG, Allen G, Haxby JV, Largay KA, Daly E, White BJ, et al. The effects of sex steroids, and the $\mathrm{X}$ chromosome, on female brain function: a study of the neuropsychology of adult Turner syndrome. Neuropsychologia. 1994;32:1309-23.

Nagy Z, Westerberg H, Skare S, Andersson JL, Lilja A, Flodmark O, et al. Preterm children have disturbances of white matter at 11 years of age as shown by diffusion tensor imaging. Pediatr Res. 2003;54:672-9.

Neil J, Shiran S, McKinstry RC, Schefft GL, Snyder AZ, Almli CR, et al. Normal brain in human newborns: apparent diffusion coefficient and diffusion anisotropy measured by using diffusion tensor MR imaging. Radiology. 1998;209:57-66.

Niklasson L, Rasmussen P, Oskarsdottir S, Gillberg C. Neuropsychiatric disorders in the 22q11 deletion syndrome. Genet Med. 2001;3:79-84.

Njiokiktjien C. Callosal dysfunction as a possible pathogenic factor in developmental dysphasia. EFCNS Symposium, Noordwijkerhout, The Netherlands. Neuropaediatrie, 12. 1983.

Njiokiktjien C, Valk J, Ramaekers G. Malformation or damage of the corpus callosum? A clinical and MRI study. Brain Dev. 1988;10:92-9.

North K. Neurofibromatosis type 1. Am J Med Genet. 2000;97:119-27.

North KN, Riccardi V, Samango-Sprouse C, Ferner R, Moore B, Legius $\mathrm{E}$, et al. Cognitive function and academic performance in neurofibromatosis. 1: consensus statement from the NF1 Cognitive Disorders Task Force. Neurology. 1997;48:1121-7.
Nosarti C, Rushe TM, Woodruff PW, Stewart AL, Rifkin L, Murray RM. Corpus callosum size and very preterm birth: relationship to neuropsychological outcome. Brain. 2004;127:2080-9.

O'Brien G. The behavioral and developmental consequences of callosal agenesis. In: Lassonde M, Jeeves MA, editors. Callosal agenesis: A natural split brain? New York: Plenum Press; 1994.

O'Hare ED, Kan E, Yoshii J, Mattson SN, Riley EP, Thompson PM, et al. Mapping cerebellar vermal morphology and cognitive correlates in prenatal alcohol exposure. NeuroReport. 2005; 16:1285-90.

Odegard TN, Farris EA, Ring J, McColl R, Black J. Brain connectivity in non-reading impaired children and children diagnosed with developmental dyslexia. Neuropsychologia. 2009;47:1972-7.

Olivares R, Michalland S, Aboitiz F. Cross-species and intraspecies morphometric analysis of the corpus callosum. Brain Behav Evol. 2000;55:37-43.

Olivares R, Montiel J, Aboitiz F, Facultad de Ciencias Veterinarias. Species differences and similarities in the fine structure of the mammalian corpus callosum. Brain Behav Evol. 2001;57 (2):98-105.

Ozonoff S. Cognitive impairment in neurofibromatosis type 1. Am J Med Genet. 1999;89:45-52.

Pandya DN, Karol EA, Heilbronn D. The topographical distribution of interhemispheric projections in the corpus callosum of the rhesus monkey. Brain Res. 1971;32:31-43.

Papolos DF, Faedda GL, Veit S, Goldberg R, Morrow B, Kucherlapati $\mathrm{R}$, et al. Bipolar spectrum disorders in patients diagnosed with velo-cardio-facial syndrome: does a hemizygous deletion of chromosome 22q11 result in bipolar affective disorder? Am J Psychiatry. 1996;153:1541-7.

Patten BM. Human embryology. New York: McGraw-Hill; 1968.

Paul LK, Van Lancker D, Schieffer B, Dietrich R, Brown WS. Communicative deficits in individuals with agenesis of the corpus callosum: nonliteral language and affective prosody. Brain Lang. 2003;85:313-24.

Paul LK, Brown WS, Adolphs R, Tyszka JM, Richards LJ, Mukherjee $\mathrm{P}$, et al. Agenesis of the corpus callosum: genetic, developmental and functional aspects of connectivity. Nat Rev Neurosci. 2007;8:287-99.

Pelphrey K, Adolphs R, Morris JP. Neuroanatomical substrates of social cognition dysfunction in autism. Ment Retard Dev Disabil Res Rev. 2004;10:259-71.

Pelphrey KA, Morris JP, McCarthy G. Neural basis of eye gaze processing deficits in autism. Brain. 2005;128:1038-48.

Peterson BS, Vohr B, Staib LH, Cannistraci CJ, Dolberg A, Schneider KC, et al. Regional brain volume abnormalities and long-term cognitive outcome in preterm infants. JAMA. 2000;284:1939-47.

Piven J, Bailey J, Ranson BJ, Arndt S. An MRI study of the corpus callosum in autism. Am J Psychiatry. 1997;154:1051-6.

Plessen KJ, Grüner R, Lundervold A, Hirsch JG, Xu D, Bansal R, et al. Reduced white matter connectivity in the corpus callosum of children with Tourette syndrome. J Child Psychol Psychiatry. 2006;47:1013-22.

Preis S, Steinmetz H, Knorr U, Jäncke L. Corpus callosum size in children with developmental language disorder. Brain Res Cogn Brain Res. 2000;10:37-44.

Rademaker KJ, Lam JN, Van Haastert IC, Uiterwaal CS, Lieftink AF, Groenendaal F, et al. Larger corpus callosum size with better motor performance in prematurely born children. Semin Perinatol. 2004;28:279-87.

Rados M, Judas M, Kostović I. In vitro MRI of brain development. Eur J Radiol. 2006;57:187-98.

Rakic P, Yakovlev PI. Development of the corpus callosum and cavum septi in man. J Comp Neurol. 1968;132:45-72. 
Rao KC, Harwood-Nash DC. Cranio-cerebral anomalies. Cranial Computed Tomography. 1983;116:147-56.

Rapin I. Practitioner review: developmental language disorders: a clinical update. J Child Psychol Psychiatry Allied Discipl. 1996;37:643-55.

Reiss AL, Abrams MT, Greenlaw R, Freund L, Denckla MB. Neurodevelopmental effects of the FMR-1 full mutation in humans. Nat Med. 1995a;1:159-67.

Reiss AL, Mazzocco MM, Greenlaw R, Freund LS, Ross JL. Neurodevelopmental effects of $\mathrm{X}$ monosomy: a volumetric imaging study. Ann Neurol. 1995b;38:731-8.

Reiss A, Eliez S, Schmitt J, Straus E, Lai Z, Jones W, et al. Neuroanatomy of Williams syndrome: a high-resolution MRI study. J Cogn Neurosci. 2000;12 Suppl 1:65-73.

Ren T, Anderson A, Shen WB, Huang H, Plachez C, Zhang J, et al. Imaging, anatomical, and molecular analysis of callosal formation in the developing human fetal brain. Anat Rec A Discov Mol Cell Evol Biol. 2006;288:191-204.

Rice ML, Oetting JB. Morphological deficits of children with SLI: evaluation of number marking and agreement. J Speech Hear Res. 1993;36:1249-57.

Riley EP, Mattson SN, Sowell ER, Jernigan TL, Sobel DF, Jones KL. Abnormalities of the corpus callosum in children prenatally exposed to alcohol. Alcohol Clin Exp Res. 1995;19:1198-202.

Ringo JL, Doty RW, Demeter S, Simard PY. Time is of the essence: a conjecture that hemispheric specialization arises from interhemispheric conduction delay. Cereb Cortex. 1994;4:331-343.

Roebuck TM, Mattson SN, RIley EP. A review of the neuroanatomical findings in children with fetal alcohol syndrome or prenatal exposure to alcohol. Alcohol Clin Exp Res. 1998;22:339-44.

Roebuck-Spencer TM, Mattson SN, Marion SD, Brown WS, Riley EP. Bimanual coordination in alcohol-exposed children: role of the corpus callosum. J Int Neuropsychol Soc. 2004; 10:536-48.

Roessner V, Banascheswski T, Uebel H, Becker A, Rothenberger A. Neuronal network models of ADHD - lateralization with respect to interhemispheric connectivity reconsidered. Eur Child Adolesc Psychiatry. 2004;13:171-9.

Rolfe MH, Kirk IJ, Waldie KE. Interhemispheric callosal transfer in adults with attention-deficit/hyperactivity disorder: an eventrelated potential study. NeuroReport. 2007;18:255-9.

Romans SM, Stefanatos G, Roeltgen DP, Kushner H, Ross JL. Transition to young adulthood in Ullrich-Turner syndrome: neurodevelopmental changes. Am J Med Genet. 1998;79:140-7.

Rosenberg DR, Keshavan MS, Dick EL, Bagwell WW, Macmaster FP, Birmaher B. Corpus callosal morphology in treatment-naive pediatric obsessive compulsive disorder. Prog Neuropsychopharmacol Biol Psychiatry. 1997;21:1269-83.

Ross JL, Stefanatos G, Roeltgen D, Kushner H, Jr Cutler GB. UllrichTurner syndrome: neurodevelopmental changes from childhood through adolescence. Am J Med Genet. 1995;58:74-82.

Ross JL, Kushner H, Zinn AR. Discriminant analysis of the UllrichTurner syndrome neurocognitive profile. Am J Med Genet. 1997;72:275-80.

Ross JL, Roeltgen D, Kushner H, Wei F, Zinn AR. The Turner syndrome-associated neurocognitive phenotype maps to distal Xp. Am J Hum Genet. 2000;67:672-81.

Ross JL, Stefanatos GA, Kushner H, Zinn A, Bondy C, Roeltgen D. Persistent cognitive deficits in adult women with Turner syndrome. Neurology. 2002;58:218-25.

Rumsey JM, Casanova M, Mannheim GB, Patronas N, De Vaughn N, Hamburger SD, et al. Corpus callosum morphology, as measured with MRI, in dyslexic men. Biol Psychiatry. 1996;39:769-75.
Sampaio A, Sousa N, Férnandez M, Vasconcelos C, Shenton ME, Gonçalves OF. MRI assessment of superior temporal gyrus in Williams syndrome. Cognitive and behavioral neurology: official journal of the Society for Behavioral and Cognitive Neurology. 2008;21:150-6.

Sanders RJ. Sentence comprehension following agenesis of the corpus callosum. Brain Lang. 1989;37:59-72.

Santhouse AM, Ffytche DH, Howard RJ, Williams SC, Stewart AL, Rooney M, et al. The functional significance of perinatal corpus callosum damage: an fMRI study in young adults. Brain. 2002;125:1782-92.

Santos A, Rondan C, Mancini J, Deruelle C. Behavioural indexes of callosal functioning in Williams syndrome. J Neuropsychol. 2007;1:189-200.

Sauerwein HC, Lassonde M. Intra- and inter-hemispheric processing of visual information in callosal agenesis. Neuropsychologia. $1983 ; 21: 167-71$.

Sauerwein HC, Nolin P, Lassonde M. Cognitive functioning in callosal agenesis. In: Lassonde M, Jeeves MA, editors. Callosal agenesis: A natural split brain? New York: Plenum Press; 1994.

Schmitt JE, Eliez S, Warsofsky IS, Bellugi U, Reiss AL. Corpus callosum morphology of Williams syndrome: relation to genetics and behavior. Dev Med Child Neurol. 2001;43:155-9.

Schulte T, Sullivan E, Müller-Oehring E, Adalsteinsson E, Pfefferbaum A. Corpus callosal microstructural integrity influences interhemispheric processing: a diffusion tensor imaging study. Cereb Cortex. 2005;15:1384-92.

Semrud-Clikeman M, Filipek PA, Biederman I, Steingard R, Kennedy D, Renshaw P, et al. Attention-deficit hyperactivity disorder: Magnetic resonance imaging morphometric analysis of the corpus callosum. J Am Acad Child Adolesc Psychiatry. 1994;33:875-81.

Shashi V, Muddasani S, Santos CC, Berry MN, Kwapil TR, Lewandowski E, et al. Abnormalities of the corpus callosum in nonpsychotic children with chromosome 22q11 deletion syndrome. Neuroimage. 2004;21:1399-406.

Shevell MI. Clinical and diagnostic profile of agenesis of the corpus callosum. J Child Neurol. 2002;17:896-900.

Simon TJ, Bearden CE, Mc-Ginn DM, Zackai E. Visuospatial and numerical cognitive deficits in children with chromosome 22q11.2 deletion syndrome. Cortex. 2005;41:145-55.

Skuse DH, James RS, Bishop DV, Coppin B, Dalton P, AamodtLeeper G, et al. Evidence from Turner's syndrome of an imprinted X-linked locus affecting cognitive function. Nature. 1997;387:705-8.

Skuse DH, Morris JS, Dolan RJ. Functional dissociation of amygdalamodulated arousal and cognitive appraisal, in Turner syndrome. Brain. 2005;128:2084-96.

Solursh LP, Margulies AI, Ashem B, Stasiak EA. The relationships of agenesis of the corpus callosum to perception and learning. J Nerv Ment Dis. 1965;141:180-9.

Sowell ER, Mattson SN, Thompson PM, Jernigan TL, Riley EP, Toga AW. Mapping callosal morphology and cognitive correlates: effects of heavy prenatal alcohol exposure. Neurology. 2001;57:235-44.

Sowell ER, Thompson PM, Welcome SE, Henkenius AL, Toga AW, Peterson BS. Cortical abnormalities in children and adolescents with attention-deficit hyperactivity disorder. Lancet. 2003; 362:1699-707.

Sowell E, Johnson AB, Kan E, Lu L, Van Horn J, Toga A, et al. Mapping white matter integrity and neurobehavioral correlates in children with fetal alcohol spectrum disorders. J Neurosci. 2008;28:1313-9.

Sperry RW. Lateral specialization in the surgically separated hemispheres. In: Schmitt F, Worden F, editors. The Neuro- 
sciences. Third study program. New York: Rockefeller University Press; 1974.

Stachon AC, Baskin B, Smith AC, Shugar A, Cytrynbaum C, Fishman $\mathrm{L}$, et al. Molecular diagnosis of 22q11.2 deletion and duplication by multiplex ligation dependent probe amplification. Am J Med Genet A. 2007;143A:2924-30.

Steen RG, Taylor JS, Langston JW, Glass JO, Brewer VR, Reddick WE, et al. Prospective evaluation of the brain in asymptomatic children with neurofibromatosis type 1: relationship of macrocephaly to T1 relaxation changes and structural brain abnormalities. AJNR Am J Neuroradiol. 2001;22:810-7.

Stein J. The magnocellular theory of developmental dyslexia. Dyslexia. 2001;7:12-36.

Stewart AL, Rifkin L, Amess PN, Kirkbride V, Townsend JP, Miller $\mathrm{DH}$, et al. Brain structure and neurocognitive and behavioural function in adolescents who were born very preterm. Lancet. 1999;353:1653-7.

Sundram F, Campbell LE, Azuma R, Daly E, Bloemen OJN, Barker GJ, et al. White matter microstructure in 22q11 deletion syndrome: a pilot diffusion tensor imaging and voxel-based morphometry study of children and adolescents. J Neurodev Disord. 2010;2:77-92.

Swillen A, Devriendt K, Legius E, Eyskens B, Dumoulin M, Gewillig $\mathrm{M}$, et al. Intelligence and psychosocial adjustment in velocardiofacial syndrome: a study of 37 children and adolescents with VCFS. J Med Genet. 1997;34:453-8.

Sykes DH, Hoy EA, Bill JM, McClure BG, Halliday HL, Reid MM. Behavioural adjustment in school of very low birthweight children. J Child Psychol Psychiatry. 1997;38:315-25.

Symington SH, Paul LK, Symington MF, Ono M, Brown WS. Social cognition in individuals with agenesis of the corpus callosum. Social Neuroscience. 2010;5:296-305.

Tabibnia G, Zaidel E. Alexithymia, interhemispheric transfer, and right hemispheric specialization: a critical review. Psychother Psychosom. 2005;74:81-92.

Tallal P, Miller S, Fitch RH. Neurobiological basis of speech: a case for the preeminence of temporal processing. Ann NY Acad Sci. $1993 ; 682: 27-47$

Tallal P, Merzenich MM, Miller S, Jenkins W. Language learning impairments: integrating basic science, technology, and remediation. Exp Brain Res. 1998;123:210-9.

Tamanini F, Meijer N, Verheij C, Willems PJ, Galjaard H, Oostra BA, et al. FMRP is associated to the ribosomes via RNA. Hum Mol Genet. 1996;5:809-13.

Temple CM, Ilsley J. Phonemic discrimination in callosal agenesis. Cortex. 1993;29:341-8.

Temple CM, Jeeves MA, Vilarroya O. Ten pen men: Rhyming skills in two children with callosal agenesis. Brain Lang. 1989;37:548-64.

Temple CM, Jeeves MA, Vilarroya O. Reading in callosal agenesis. Brain Lang. 1990;39:235-53.

Tomaiuolo F, Di Paola M, CARAVALE B, Vicari S, Petrides M, Caltagirone C. Morphology and morphometry of the corpus callosum in Williams syndrome: a T1-weighted MRI study. NeuroReport. 2002;13:2281-4.

Tovar-Moll F, Moll J, De Oliveira-Souza R, Bramati I, Andreiuolo PA, Lent R. Neuroplasticity in human callosal dysgenesis: a diffusion tensor imaging study. Cereb Cortex. 2007;17:531-41.

Truhan A, Filipek P. Magnetic resonance imaging. Its role in the neuroradiologic evaluation of neurofibromatosis, tuberous sclerosis, and Sturge-Weber syndrome. Arch Dermatol. 1993;129:219-26.
Turk A, Brown WS, Symingtion M, Paul LK. Social narratives in agenesis of the corpus callosum: linguistic analysis of the thematic apperception test. Neuropsychologia. 2010;48:43-50.

Ullman MT, Gopnik M, editors. The production of inflectional morphology in hereditary specific language impairment. Montreal: McGill; 1994.

Ullman MT, Pierpont EI. Specific language impairment is not specific to language: the procedural deficit hypothesis. Cortex; a journal devoted to the study of the nervous system and behavior. 2005;41:399-433.

Valera EM, Faraone SV, Murray KE, Seidman LJ. Meta-analysis of structural imaging findings in attention-deficit/hyperactivity disorder. Biol Psychiatry. 2007;61:1361-9.

Van Amelsvoort T, Daly E, Robertson D, Suckling J, Ng V, Critchley $\mathrm{H}$, et al. Structural brain abnormalities associated with deletion at chromosome 22q11: quantitative neuroimaging study of adults with velo-cardio-facial syndrome. $\mathrm{Br} \mathrm{J}$ Psychiatry. 2001;178:412-9.

Van Dyke DL, Wiktor A, Roberson JR, Weiss L. Mental retardation in Turner syndrome. J Pediatr. 1991;118:415-7.

Vidal CN, Nicolson R, Devito TJ, Hayashi KM, Geaga JA, Drost DJ, et al. Mapping corpus callosum deficits in autism: an index of aberrant cortical connectivity. Biol Psychiatry. 2006;60:218-25.

Wahl M, Lauterbach-Soon B, Hattingen E, Jung P, Singer O, Volz S, et al. Human motor corpus callosum: topography, somatotopy, and link between microstructure and function. J Neurosci. 2007;27:12132-8.

Waiter GD, Williams JH, Murray AD, Gilchrist A, Perrett DI, Whiten A. Structural white matter deficits in high-functioning individuals with autistic spectrum disorder: a voxel-based investigation. Neuroimage. 2005;24:455-61.

Wang PP, Woodin MF, Kreps-Falk R, Moss EM. Research on behavioral phenotypes: velocardiofacial syndrome (deletion 22q11.2). Dev Med Child Neurol. 2000;42:422-7.

Wang LW, Huang CC, Yeh TF. Major brain lesions detected on sonographic screening of apparently normal term neonates. Neuroradiology. 2004;46:368-73.

Wiegell MR, Larsson HB, Wedeen VJ. Fiber crossing in human brain depicted with diffusion tensor MR imaging. Radiology. 2000;217:897-903.

Willemsen R, Oostra BA, Bassell GJ, Dictenberg J. The fragile X syndrome: from molecular genetics to neurobiology. Ment Retard Dev Disabil Res Rev. 2004;10:60-7.

Witelson SF. The brain connection. The corpus callosum is larger in left-handers. Science. 1985;229:665-8.

Witelson SF. Hand and sex differences in the isthmus and genu of the human corpus callosum. A postmortem morphological study. Brain. 1989;112:799-835.

Wozniak JR, Muetzel RL, Mueller BA, McGee CL, Freerks MA, Ward EE, et al. Microstructural corpus callosum anomalies in children with prenatal alcohol exposure: an extension of previous diffusion tensor imaging findings. Alcohol Clin Exp Res. 2009;33(10):1825-35.

Zaidel D, Sperry RW. Some long-term motor effects of cerebral commissurotomy in man. Neuropsychologia. 1977;15:193204.

Zamboni SL, Loenneker T, Boltshauser E, Martin E, Il'Yasov KA. Contribution of diffusion tensor MR imaging in detecting cerebral microstructural changes in adults with neurofibromatosis type 1. AJNR Am J Neuroradiol. 2007;28:773-6. 